\title{
ORNL Neutral Gas Shielding Model for Pellet-Plasma Interactions
}

\author{
S. L. Milora \\ C. A. Foster
}

\section{OAK RIDGE NATIONAL LABORATORY}




\section{DISCLAIMER}

This report was prepared as an account of work sponsored by an agency of the United States Government. Neither the United States Government nor any agency Thereof, nor any of their employees, makes any warranty, express or implied, or assumes any legal liability or responsibility for the accuracy, completeness, or usefulness of any information, apparatus, product, or process disclosed, or represents that its use would not infringe privately owned rights. Reference herein to any specific commercial product, process, or service by trade name, trademark, manufacturer, or otherwise does not necessarily constitute or imply its endorsement, recommendation, or favoring by the United States Government or any agency thereof. The views and opinions of authors expressed herein do not necessarily state or reflect those of the United States Government or any agency thereof. 


\section{DISCLAIMER}

Portions of this document may be illegible in electronic image products. Images are produced from the best available original document. 


\section{Printed in the United States of America. Available from National Technical Information Service \\ U.S. Department of Commerce 5285 Port Royal Road, Springfield, Virginia 22161 \\ Price: Printed Copy $\$ 4,50$; Microfiche $\$ 3.00$}

This report was prepared as an account of work sponsored by the United States Government. Neither the United States nor the Energy Research and Development Administration/United States Nuclear Regulatory Commission, nor any of their employees, nor any of their contractors, subcontractors, or their employees, makes any warranty, express or implied, or assumes any legal liability or responsibility for the accuracy, completeness or usefulness of any information, apparatus, product or process disclosed, or represents that its use would not infringe privately owned rights. 
Contract No. W-7405-eng-26

Fusion Energy Division

ORNL NEUTRAL GAS SHIELDING MODEL FOR PELLET-PLASMA

INTERACTIONS

S. L. Milora

C. A. Foster

This report was prepared as an account of work sponsored by the United States Government. Neither Research and Dovelopment Adminiatrotion nor any of their employees, not any of their contractors. subcontractors, or their employees, makes any
wartanty, express or implied, or assumes any legal wartanty, express or implied, or assumes any legal
liability or responsibility for the arsurary. rnmpleteness or usefulness of any information, apparatus, product or proecss disclised, un iepiceernls that its use would not infringe privately owned rights.

(to be submitted to Nuclear Fusion)

Date Published: May 1977

NOTICE This document contains information of a preliminary nature. It is subject to revision or correction and therefore does not represent a final report.

Prepared by the

OAK RIDGE NATIONAL LABORATORY

Oak Ridge, Tennessee

operated by

UNION CARBIDE CORPORATION

for the

ENERGY RESEARCH AND DEVELOPMENT ADMINISTRATION 


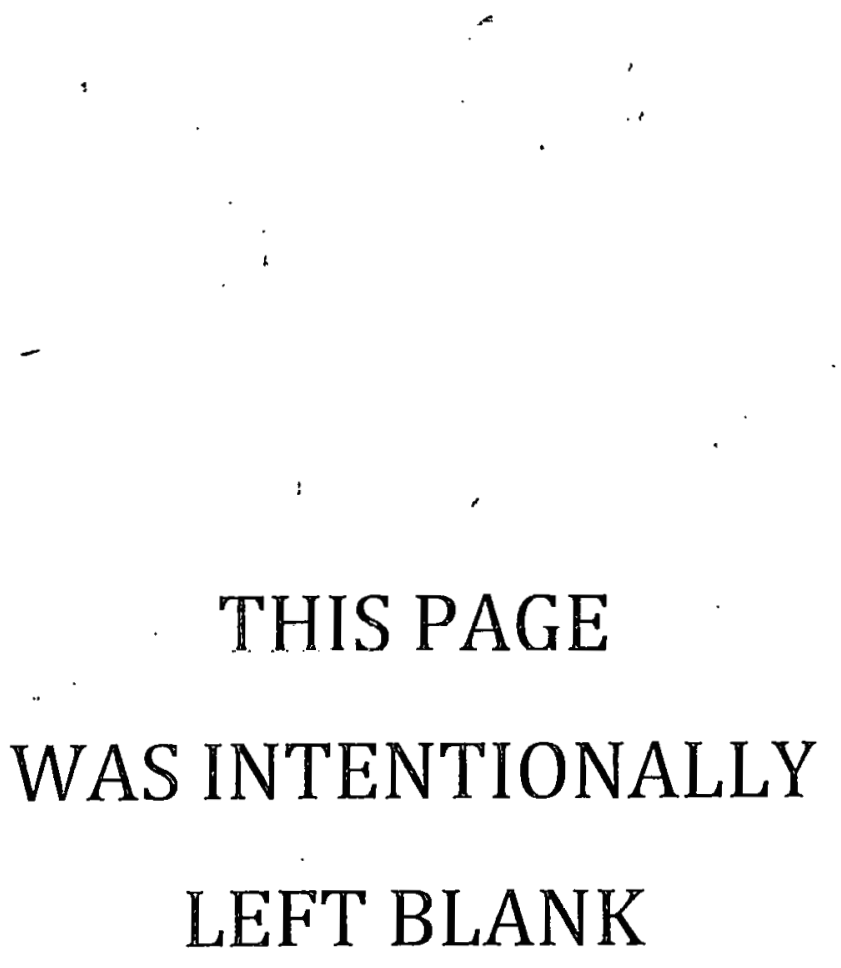


CONTENTS

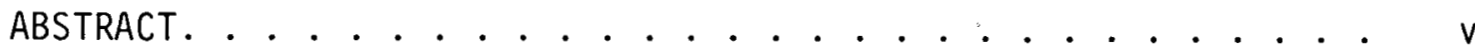

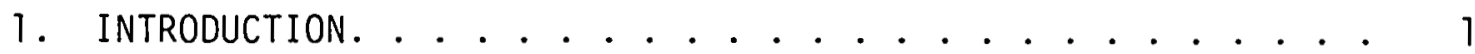

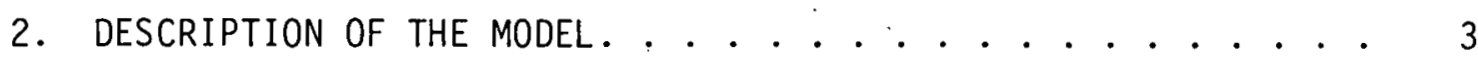

2.1 The Conservation Equations ........... 3

2.2 The Hydrodynamics of the Shielding CToud . . . . . 8

2.3 The Equation of the Shield ........... 16

3. THE DYNAMICS OF THE ABLATION PROCESS. . . . . . . . . . 19

3.1 The Generalized Ablation Rate Equation........ 19

3.2 Implications of the Shield . . . . . . . . . 20

3.3 Approximate Pellet Lifetime Scaling Law. . . . . . . . 22

4. COMPARISON WITH ORMAK EXPERIMENTS . . . . . . . . . . . . 25

4.1 Experimental Results and Plasma Conditions . . . . . 25

4.2 Revised Ablation Rate Equation . . . . . . . . . 29

4.3 Comparison with Experiment . . . . . . . . . 30

5. PELLET FUELING APPARATUS DESIGN CONSIDERATIONS. . . . . 39

5.1 Pellet Velocity Scaling Law. . . . . . . . . 39

5.2 Estimate of Fueling Parameters for Major Experimental Devices.............. . . 43

NOMENCLATURE AND UNITS. . . . . . . . . . . . . . . 45

REFERENCES. . . . . . . . . . . . . . . 47

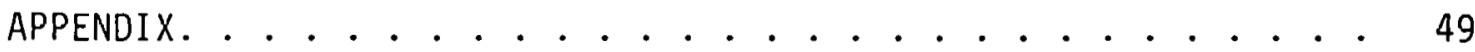


THIS PAGE

WAS INTENTIONALLY

LEFT BLANK 
A revised neutral molecule ablation model is derived to describe the evaporation of a solid hydrogen pellet in a tokamak plasma. The approach taken is based on the theory of Parks, Turnbull, and Foster who postulate that a cloud of molecular hydrogen surrounding the pellet shields the surface from incoming energetic electrons and, in so doing, regulates the evaporation rate. This treatment differs from an earlier model in that the hydrodynamic behavior of the molecular cloud is treated in a self-consistent manner. Numerical solutions of the fluid dynamic equations, which include the effects of strong electron heating locally in the gas, reveal that the flow of material away from the pellet is initially retarded by the heating and then rapidly accelerated and rarefied. This behavior is more pronounced for higher temperature plasmas and the net effect is that pellet lifetimes are prolonged slightly by including the heating effects.

A comparison is made with the results of the recent pellet injection experiments on ORMAK and a simple injection depth scaling law is derived. 


\section{INTRODUCTION}

In this report we describe a simple model for determining the basic elements of the pellet-plasma interaction, namely, the pellet surface ablation rate and the consequent pellet lifetime. This information is essential for the design of a pellet fueling apparatus which must inject hydrogen to the interior of the hot plasma of a tokamak.

This work extends the theory of Parks et al. 1 by treating, in more detail, the hydrodynamic behavior of the cloud of molecular hydrogen that is formed by the ablation process. In the original model, the hydrodynamic treatment was simplified by assuming that the flow of material away from the pellet surface was sonic everywhere. In the following analysis, the sonic flow approximation is discarded and self consistent hydrodynamic solutions are obtained. This aspect of the problem is important in that the ablatant surrounding the pellet partially shields the surface from incident electrons by providing a medium in which electrons suffer inelastic collisions and are degraded in energy. The presence of this neutral gas shielding layer is the essential element of the theory, since it alone regulates the rate of evaporation of material from the pellet surface. This is a consequence of the hypothesis that molecules of hydrogen (not ion pairs) evaporate from the pellet surface and that the energy required for this solid-to-gaseous phase change is small in comparison with the energy of the plasma particles $(0.01 \mathrm{eV}$ vs $\sim 100 \mathrm{eV}$ ). In this respect the problem resembles a particular case of the evaporation of a liquid droplet in which the evaporation rate is limited by the transport of heat from the external medium through the surrounding vapor. 


\section{THIS PAGE}

WAS INTENTIONALLY

LEFT BLANK 


\section{DESCRIPTION OF THE MODEL}

\subsection{THE CONSERVATION EQUATIONS}

The pellet ablation process considered here is regulated by the rate at which energy is delivered to the pellet surface by incident energetic particles. It is assumed that electrons alone are responsible for providing the heat that sustains the evaporation process. The relatively cold and dense hydrogen gas formed at the surface expands into the nearvacuum conditions of the background plasma where it is subsequentiy ionized. The nature of the expansion process is characterized and dominated by extremely strong local heating due to electrons undergoing inelastic collisions in the cloud. According to the model, plasma electrons penetrate the cloud as a Maxwellian beam confined to magnetic field lines. As a first approximation, attenuation of the beam intensity by elastic scattering is not considered but degradation of the thermal energy is included as described above. In the appendix, elastic scattering is shown to have only a small effect on the ablation rate. In any case, beam attenuation only prolongs pellet lifetimes, so this approach is conservative.

Following Parks et al., we characterize the dynamics of the evaporation process by a set of conservation equations applied at the receding pellet surface. As seen by an observer moving with the evaporation front, the mass flow of material, $\dot{m}$, crossing the pellet surface (spherical) is given in terms of the instantaneous pellet radius $r_{0}(t)$ and the mass density of the solid $\rho_{s}$ by the following expression

$$
\dot{m}=-4 \pi \rho s r_{0}^{2} \frac{d r_{0}}{d t} \text {. }
$$

In the steady state, this flow is just balanced by the rate at which vapor is convecled away frum llie pellet surface, i.e.,

$$
\dot{m}=4 \pi \rho_{0} r_{0}^{2} v_{0}
$$

where $\rho_{0}$ is the mass density of vapor at the interface and $v_{0}$ is the velocity at which it is directed away from the surface (see Fig. 1). 


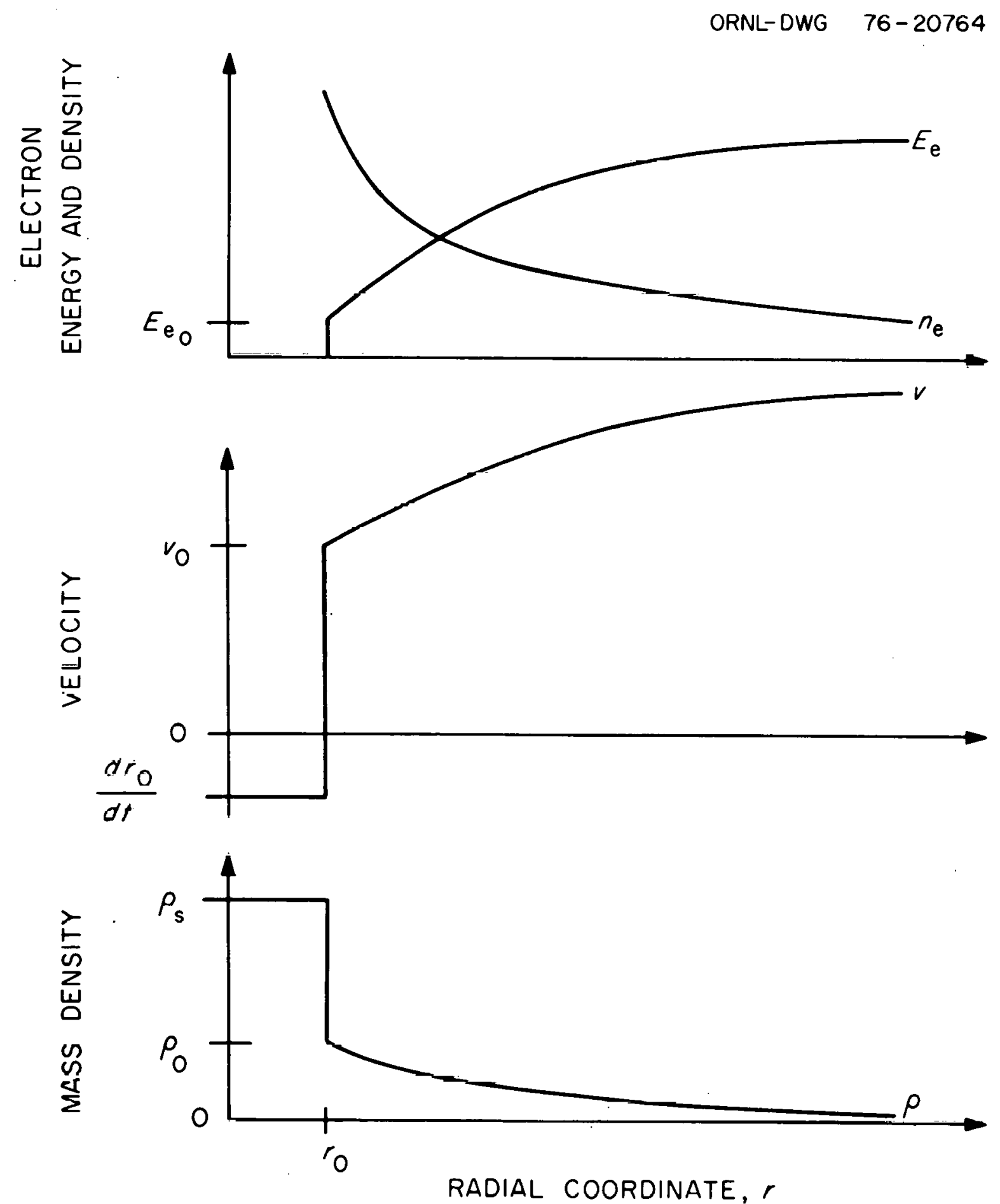

Fig. 1. Pellet coordinate system showing variation of relevant pellet-plasma parameters. 
For spherically symmetric expansions, the density and velocity of the gas are functions only of the radial position $r$ and the time $t$; their values are specified in space by the conservation equations of fluid dynamics. In this treatment a quasi-steady solution is sought which essentially allows the entire flow to adjust instantaneously as the pellet radius and gross plasma conditions change. This approximation is valid in most instances, since the time scale for this adjustment is small in comparison to typical pellet lifetimes (tens of microseconds as compared with milliseconds). Details of the hydrodynamic calculations are presented in Sect. 2.2 .

To complete the physical description of the ablation process, two additional relationships are required: (1) an energy balance at the solid interface which equates the incoming heat flux to the energy requirement for the solid-to-gaseous phase change and (2) a relationship between the plasma heat flux (electrons) external to the gas cloud and the degraded heat flux at the pellet surface. If the electron population at the interface can be characterized by a Maxwellian distribution at temperature $T_{e o}$, with mean thermal speed $\bar{C}_{e o}$ and density $n_{e o}$, then the power $\dot{Q}$ incident on the surface $A$ is given from kinetic theory by the expression

$$
\begin{aligned}
\dot{i} & =\frac{{ }_{\mathrm{eo}} \overline{\mathrm{C}}_{\mathrm{eo}}}{4} \cdot 2 \mathrm{eT} \mathrm{T}_{\mathrm{eo}} A \\
& \equiv \frac{{ }_{\mathrm{eo}} \overline{\mathrm{C}} \mathrm{eo}}{3} \cdot \mathrm{eE}_{\mathrm{eo}} \mathrm{A}
\end{aligned}
$$

where $E_{e o}=3 / 2 \tilde{T}_{e o}$ represents the mean electron thermal energy in electron volts, $\bar{C}_{e}=\sqrt{16 \mathrm{eE}_{e} / 3 \pi m_{e}}$ is the thermal speed, and $A$ is the effective cross section for interception of electrons. In the steady state, this heat flux is balanced by the amount of cooling provided by the evaporated material,

$$
\dot{Q}=\dot{m e} \lambda
$$

where $\lambda$ represents the latent heat of evaporation (in electron volts per kilogram) in the transition from solid to vapor phases and $e$ equals $1.602 \times 10^{-19}$ joules/ev. 
Finally, the electron energy $E_{\text {eo }}$ at the interface is related to the plasma energy $E_{e^{\infty}}$ and the density of the ablation cloud by a differential equation that describes the penetration of electrons through the shield as a continuous slowing-down process. Following Miles et al., 2 we introduce the function $L\left(E_{e}\right)$ which represents the cumulative electron energy loss due to inelastic collisions,

$$
\frac{d E_{e}}{d r}=\frac{\rho(r)}{m} L\left(E_{e}\right)
$$

or

$$
\int_{E_{E u}}^{E_{e}} \frac{d E_{Q}}{L\left(E_{e}\right)}=\frac{1}{m} \int_{r_{u}}^{\infty} \rho(r) d r
$$

where $m$ is the molecular mass of the ablatant. Values of $L\left(E_{e}\right)$ have been determined by Miles et al. ${ }^{2}$ for monoenergetic electrons in the energy range $I \leq E_{e}<10 \mathrm{keV}$, which is adequate for this discussion. Figure 2 shows the published data along with an approximate analytical representation. The analytical form does not exhibit discontinuities corresponding to thresholds for the various inelastic processes. A smoothed fit is justified here since we are considering a thermalized beam in which discontinuities have been removed by the process of ensemble averaging.

As mentioned before, current attenuation due to elastic scattering is neglected. In particular, we are taking the flux at the surface equal to $n_{e_{\infty}} C_{e^{\infty}} / 4$. Implicit in this statement is the assumption that charging of the pellet and consequent attenuation of the electron current is not important. The argument offered in support of this assumption is that hot incoming electrons create many cold secondary electrons (and ions) in the gas cloud which effectively short out the plasma sheath that might otherwise shield the surface.

The only remaining unknown in $\mathrm{Eq}$. (3) is the surface energy $E_{e 0}$ which is determined by Eq. (5). The effective cross section, $A$, is twice the projected area of the pellet $\left(2 \pi r_{0}^{2}\right)$ since only electrons within the shadow of the pellet will intercept the surface. The final expression for the ablation rate reduces to

$$
\frac{d r_{0}}{d t}=-\frac{n_{e^{\infty}}}{\rho_{s} \lambda} \sqrt{\frac{4 e E_{e^{\infty}}}{27 \pi m_{e}}} E_{e o} .
$$




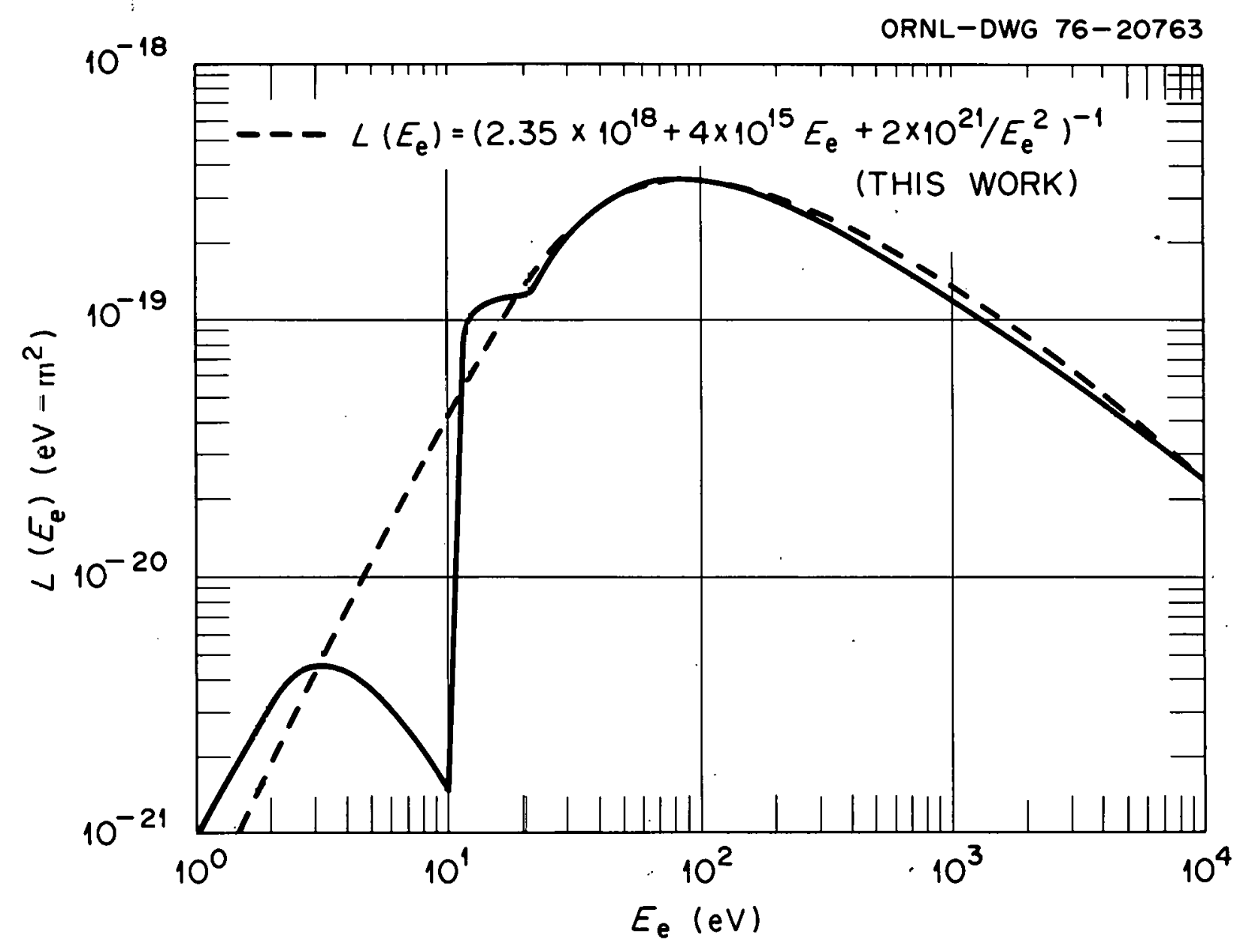

Fig. 2. Energy loss function for monoenergetic electrons in molecular hydrogen: Ref. 2 analytical approximation (this work). 
Equation (6) simply expresses energy conservation at the pellet surface. When the solution to Eq. (5) for the surface energy $E_{e o}$ is used in Eq. (6), it determines the temporal behavior of the pellet radius as a function of the local plasma parameters $n_{e_{\infty}}$ and $E_{e_{\infty}}$. Equation (5) requires knowledge of the loss function $L\left(E_{e}\right)$ and the spatial variation of the cloud density. The latter is itself an implicit function of the ablation rate through $\mathrm{Eq}$. (1) and the boundary condition implied by Eq. (2), i.e.,

$$
\rho_{0} v_{0}=\rho\left(r_{0}\right) v\left(r_{0}\right)=-\rho_{s} \frac{d r_{0}}{d t}
$$

The indeterminacy is resolved by considering the hydrodynamic behavior of the gas cloud, as discussed in Sect. 2.2.

\subsection{THE HYDRODYNAMICS OF THE SHIELDING CLOUD}

The behavior of the ablatant after it leaves the pellet surface is governed by the conservation equations of fluid dynamics. Assuming spherical symmetry and neglecting (for mathematical simplicity) temporal. variations in the flow variables, the equations of mass, momentum, and energy conservation reduce to

mass: $\quad d r\left(p v r^{2}\right)=0$

momentum: $\quad \frac{d}{d r}\left(\rho v^{2} r^{2}\right)+r^{2} \frac{d p}{d r}=0$

energy: $\quad \frac{1}{r^{2}} \frac{d}{d r}\left\{\rho v r^{2}\left(h+\frac{1}{2} v^{2}\right)\right\}=\dot{q}$

where $\rho, v, p, h$, and $\dot{q}$ represent respectively the mass density, velocity, fluid pressure, specific enthalpy, and the rate of volumetric heat generation.

In accordance with Eq. (5), the volumetric rate of heat deposition by electron collisions is

$$
\dot{q}=e J_{e} \frac{d E_{e}}{d r}=e J_{e} \frac{\rho}{m} L\left(E_{e}\right)
$$


where $J_{e}$, the electron particle flux, is given by

$$
J_{e}=\frac{n_{e^{\infty}} \bar{C}_{e^{\infty}}}{4}=n_{e_{\infty}} \sqrt{\frac{e E_{e^{\infty}}}{3 \pi m_{e}}}
$$

Equation (8) has the trivial solution

$$
r^{2} \rho v=\text { const }=r_{0}^{2} \rho_{0} v_{0}=-r_{0}^{2} \rho_{s} \frac{d r_{0}}{d t}
$$

The last result, which follows from mass conservation applied across the interface, effectively introduces the ablation rate into the fluid dynamic description.

At moderate pressures the fluid behaves like a dilute gas, and ideal gas relationships can be used to express the thermodynamic variables in Eqs. (8)-(10) in terms of the local sound speed, $a_{s}=\sqrt{\gamma \mathrm{kT} / m}$, where $\gamma$ represents the ratio of specific heats. Then, if the Mach number $M=v / a_{s}$ is introduced, Eqs. (8) through (13) can be recast into the familiar dimensionless forms 3

$$
\begin{aligned}
& \text { electron heating } \\
& \left(1-M^{2}\right) \frac{d M}{d r^{\prime}}=\frac{1}{2}\left(\frac{\rho_{0}}{\rho_{s}}\right)^{3}\left|\frac{d r_{u}}{d t}\right|^{-3} \frac{e L\left(E_{e}\right)}{m} J_{e^{r}} r_{0}(\gamma-1) \rho^{\prime} r^{\prime} 6 M^{3}\left(\gamma M^{2}+1\right) \\
& \overbrace{}^{\text {expansion cooling }} \\
& -\frac{2 M}{r^{\prime}}\left(1+\frac{r}{2}-1 M^{2}\right) \\
& \frac{d}{d r^{\prime}}\left(\rho^{\prime} r^{\prime 2}\right)^{-1}+\frac{r^{\prime} 2}{r} \frac{d}{d r^{\prime}}\left(M^{2} \rho^{\prime} r^{\prime 4}\right)^{-1}=0
\end{aligned}
$$

where $r^{\prime}=r / r_{0}$ and $\rho^{\prime}=\rho / \rho_{0}$. With this result, the flow field is completely specified by $\gamma(5 / 3$ for a monatomic gas, $7 / 5$ for a diatomic gas) and the dimensionless group

$$
\xi=\frac{(\gamma-1)}{2}\left(\frac{\rho_{0}}{\rho_{s}}\right)^{3 \text { e } L\left(E_{e}\right)} \frac{J}{m} \mathrm{~J}_{0}\left|\frac{d r_{0}}{d t}\right|^{-3}
$$


This parameter is a measure of the ratio of the energy flux due to heat transport by electron-molecule collisions to the flux of gas kinetic energy at the pellet surface. It is important from the standpoint that $\xi$ contains the ablation rate and plasma parameters through Eq. (12). A simple scaling law follows from consideration of this parameter alone.

The solution of Eq. (14) is complicated by the fact that the electron energy, and hence $L\left(E_{e}\right)$, varies with radial position according to Eq. (5). To simplify matters, $L\left(E_{e}\right)$ is assumed to be a constant equal to the value corresponding to some intermediate electron energy. This does not introduce large errors since only the integrated cloud density is required to describe the shielding of the pellet and $L\left(E_{e}\right)$ is not a sensitive function of electron energy. Anticipating that the cloud is very effective in degrading the electron energy to low values at the pellet surface, we take as typical $\left\langle L\left(E_{e}\right)\right\rangle=L\left(E_{e^{m}} / 2\right)$.

The importance of heating of the gas cloud is determined by the magnitude of $\xi$. An estimate of this effect can be made by considering the alternate form

$$
\begin{aligned}
& \xi=\frac{(\gamma-1)}{2} \text { e } \frac{\left\langle L\left(E_{e}\right)\right\rangle}{m} \frac{r_{0}}{v_{0}^{3}} \cdot J \\
& \cong 10^{12} n_{e^{\infty}} \sqrt{E_{e^{\infty}}} \frac{r_{0}}{v_{0}^{3}} L\left(E_{e^{\infty}} / 2\right)
\end{aligned}
$$

where Eqs. (7) and (12) have been used to eliminate the ablation rate and electron particle flux. As typical plasma parameters we take $E_{e w}-1 \mathrm{kcV}$ and $n_{e w}-3 \times 10^{19} / \mathrm{m}^{3}$. The nvernac loss function $i s$ found from Fig. 2 to be $L\left(E_{\mathrm{e}^{\infty}} / 2\right)=2 \times 10^{-19} \mathrm{eV}-\mathrm{m}^{2}$. Assuming the surface velocity of the ablatant $v_{0}$ to be equal to the sound speed of low temperature hydrogen gas $(\sim 400 \mathrm{~m} / \mathrm{sec})$ we find $\xi$ to be on the order of 3000 for a 1 -mm-radius pellet. This suggests that the effect of heating will be dominant for all tokamak plasmas except possibly the very tenuous low temperature edge plasmas. This could have a pronounced effect on the ablation rate since the shielding cloud is rapidly accelerated and hence rarefied by the strong heating. 
In the absence of heating, Eq. (14) can be solved directly for the Mach number as a function of radial position. The appropriate solution for a simple expansion into vacuum is the one in which $M$ is unity at the pellet surface and increases with distance from the surface. In this way, the temperature and pressure both decrease continuously. This solution is well behaved since, for $M>1$, the sign of $d M / d r^{\prime}$ is positive everywhere. When heating is included, the situation becomes more complex since, to obtain a continuously increasing Mach number solution, the right-hand side of Eq. (14) must be positive for $M<1$, negative for $M>1$, and zero for $M=1$. The latter condition is required to avoid a singularity at the sonic point. To find this transonic solution, the Mach number at the pellet surface must be uniquely chosen $\left(M_{0}<1\right)$ and this serves as the boundary condition for the problem.

Numerical solutions of this kind were found for values of the parameter $\xi$ varying between 10 and 1000 . The results of the calculation are shown in Figs. 3 and 4 in the form of the Mach number and normalized density profiles as well as the profiles of normalized temperature $T^{\prime}$, pressure $p^{\prime}$, and velocity $v^{\prime}$. The latter auxiliary variables were obtained from the Mach number and density profiles through the relationship of mass conservation, the ideal gas law, and the definition of the Mach number, i.e.,

$$
\begin{aligned}
& v^{\prime} \rho^{\prime} r^{\prime 2}=1 \\
& p^{\prime}=\rho^{\prime} T^{\prime} \\
& \frac{M}{M_{0}}=\frac{v^{\prime}}{\sqrt{T^{\prime}}}
\end{aligned}
$$

The solutions reveal some interesting trends. As anticipated, the heating drives the Mach number below unity at the pellet surface; as the heating increases, the initial flow becomes more subsonic. In these examples, the Mach number approaches a limit of 22 at distances of a few pellet radi $i$ from the surface. When an asymptotic Mach number exists, it is not difficult to show that its value must be $\sqrt{5 / \gamma}=1.89$, since the 


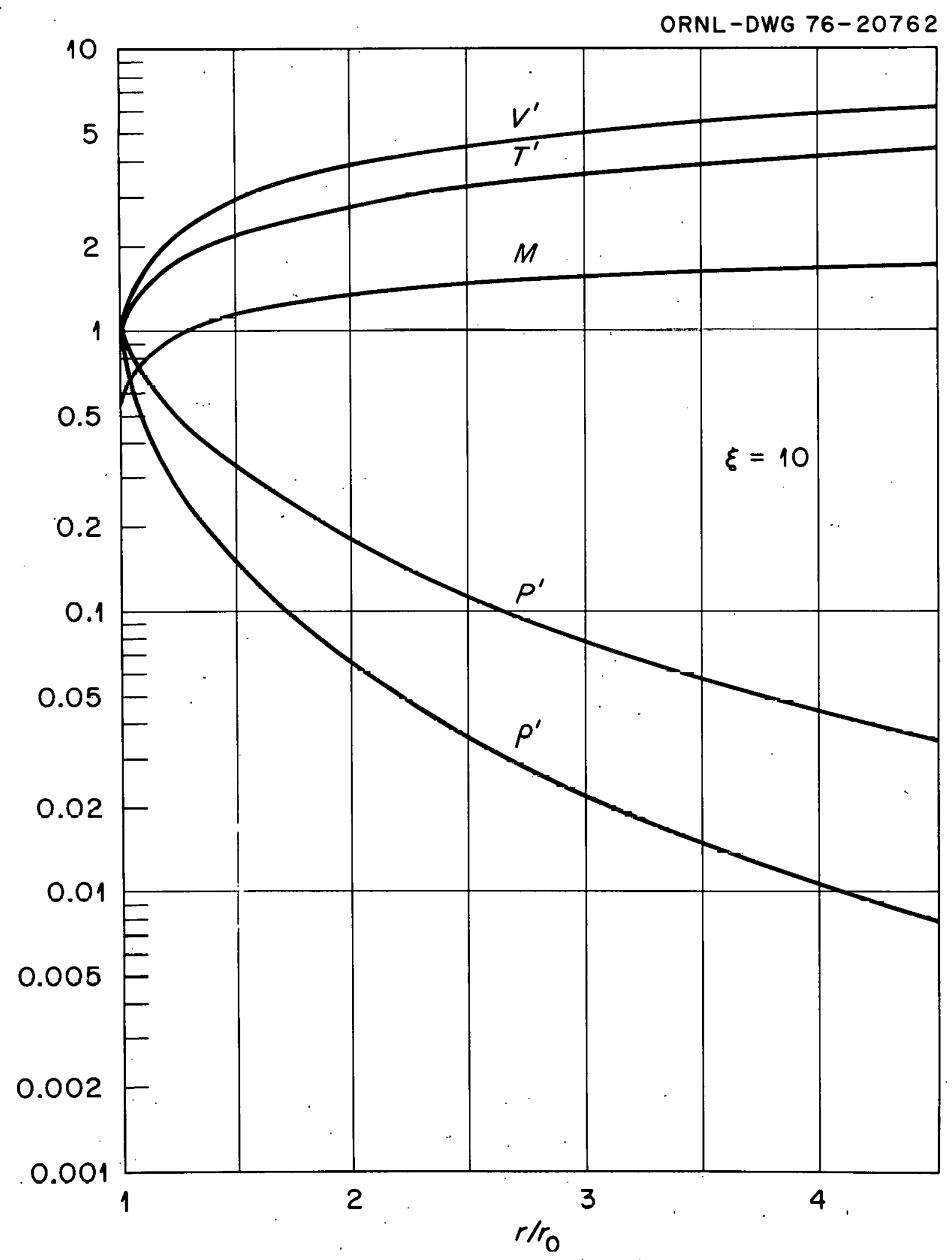

Fig. 3. Variation of normalized gasdynamic variables with radial coordinate: heating parameter $=10$. 


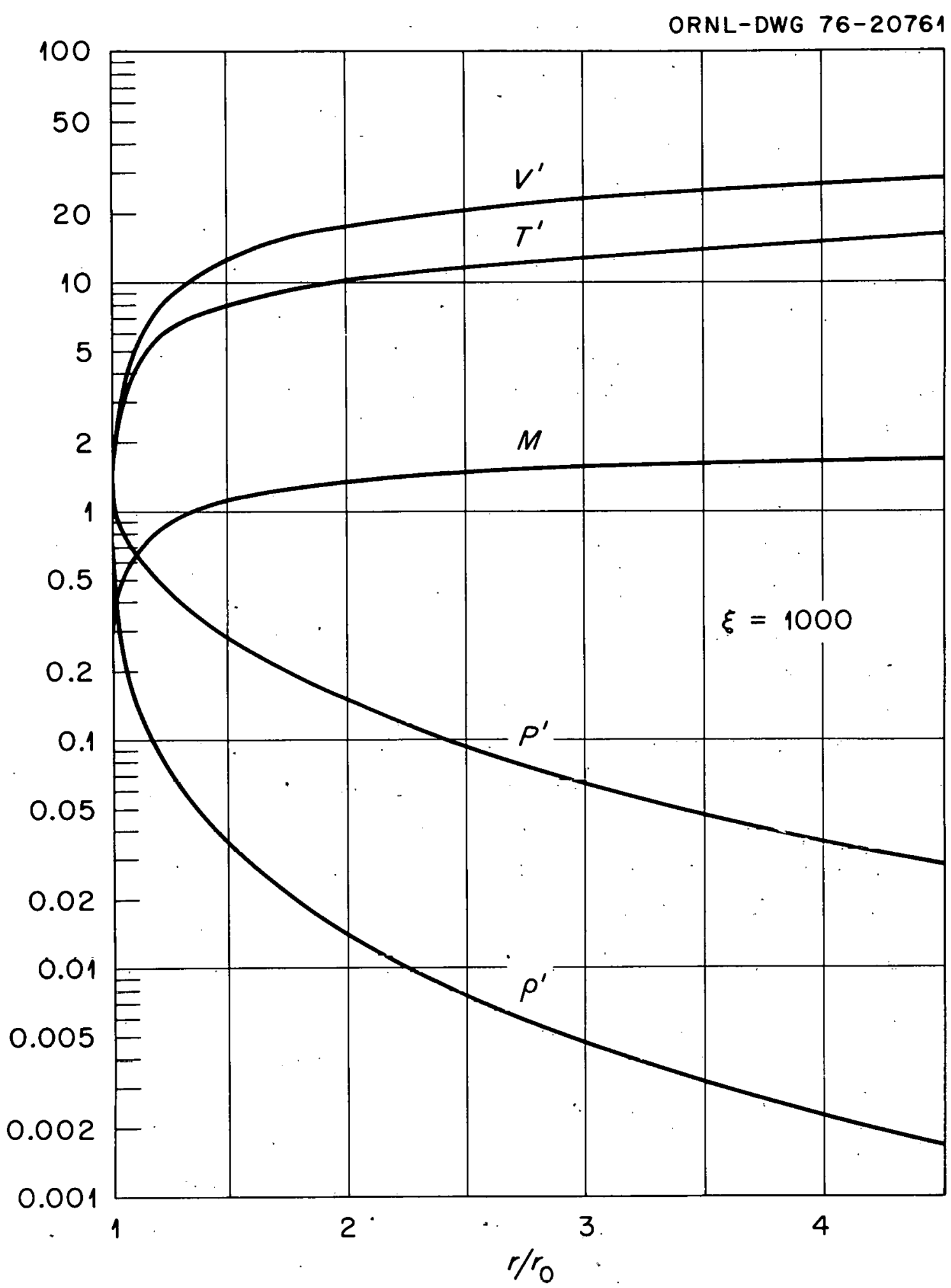

Fig. 4. Variation of normalized gasdynamic variables with radial coordinate: heating parameter - 1000. 
density profile [solution to Eq. (15) for $M=\sqrt{5 / \gamma}$ ] resulting from this value of $M$ ensures that both terms on the right-hand side of Eq. (14) approach zero at the same rate. This preserves the nature of the transonic solution by ensuring that the flow does not revert to the subsonic case.

The profiles of temperature and velocity increase monotonically while the pressure decreases as expected. It is interesting to note that, for the strong heating case, the temperature has increased by less than a factor of 20 over the surface value at the 4-pellet-radij position. Since the surface temperature is on the order of $20 \mathrm{~K}$ (cryogenic hydrogen), the temperature in the exterior of the cloud is not large. This is justification for neglecting thermal dissociation and ionization in the analysis.

The most important parameter is the density $\rho^{\prime}$ and this decreases by nearly three orders of magnitude over a distance of a few pellet radi $i$ for the case $\xi=1000$. This verifies the assumption that heating rapidly rarefies the cloud. It also indicates that the shielding "layer" is confined to a region very close to the pellet surface. This verifies the quasi-steady-state approximation since the flow must adjust over only a very short distance to accommodate changing plasma conditions.

The calculation also provides an expression for the integrated column density needed to evaluate Eq. (5b). Figure $\overline{5}$ shows the dependence of the normalized target thickness on the parameter $\xi$. The resuits can be summarized by a function, $f(\xi)$, defined as

$$
\int_{1}^{\infty} \theta^{\prime} d r^{\prime}-r(\xi)=\int_{r_{0}}^{\omega} \frac{\rho d r}{\theta_{0} r_{0}} .
$$

As expected, $f(\xi)$ decreases with increasing $\xi$, which reflects the dilution of the cloud caused by heating. Also shown is the variation of the surface Mach number $M_{0}$. The decreasing trend indicates that the velocity of the ablatant is lowered by heating. In other words, the flow is "bottled up," or retarded, at the surface. This effect tends to offset the dilution of the cloud by heating since the variation in $M_{0}$ roughly parallels that of $f(\xi)$. 


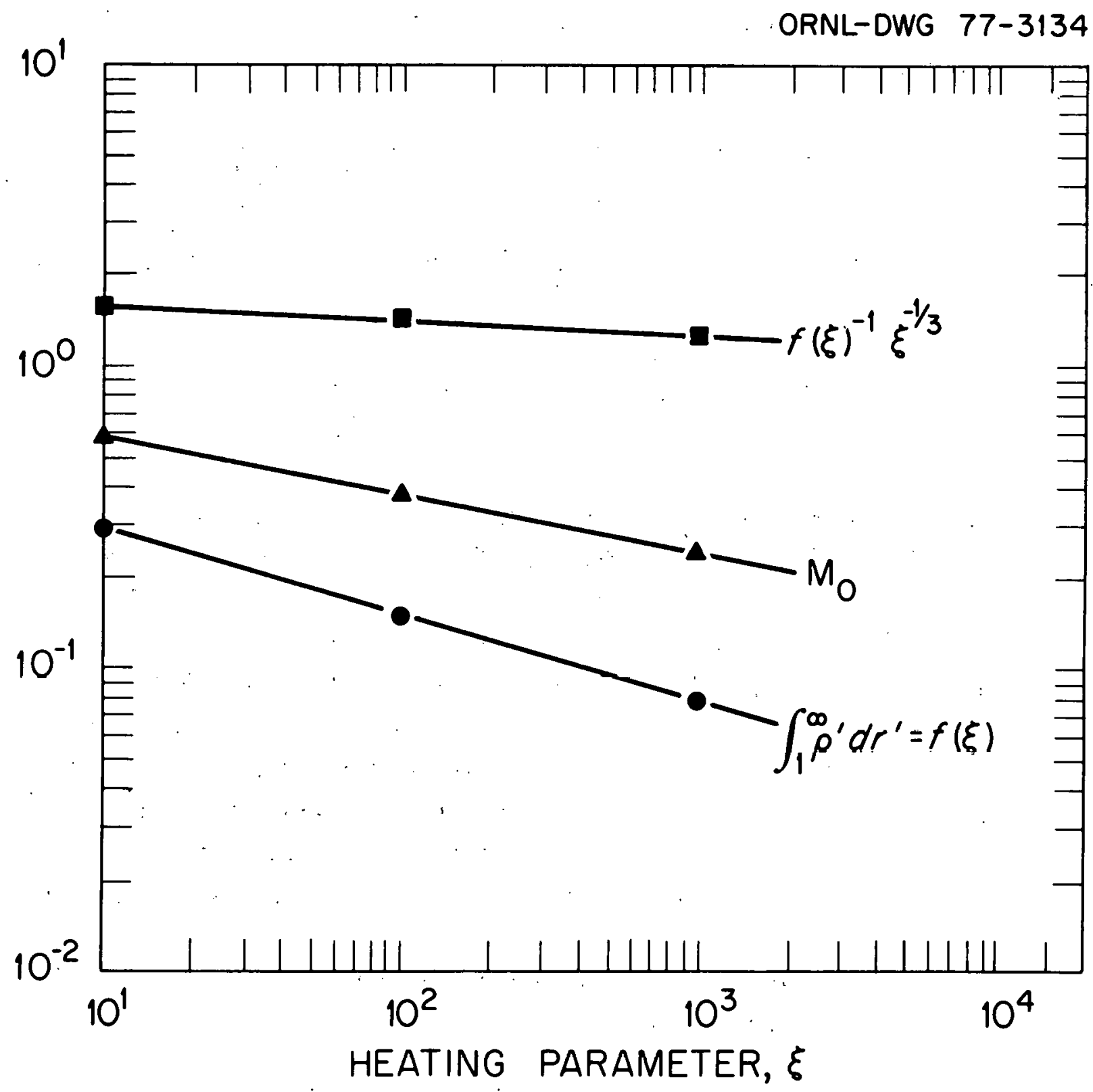

Fig. 5. Variation of normalized integrated column density, pellet surface Mach number, and ablation rate coefficient with heating parameter $\xi$. 


\subsection{THE EQUATION OF THE SHIELD}

With the result of the preceding section, a companion to Eq. (6) can be written to describe the amount of material that the pellet must expel in order to degrade the electron energy to the value $E_{e o}$. This follows directly from the definition of $\xi$ :

$$
\left|\frac{d r_{0}}{d t}\right|=\frac{\rho_{0}}{\rho_{s}} \xi^{-1 / 3}\left\{\frac{(\gamma-1)}{2} \text { e } \frac{\left\langle L\left(E_{e}\right)\right\rangle}{m} J_{e} r_{0}\right\}^{1 / 3} .
$$

The surface density $\rho_{\dot{u}}$ is eliminated through Eqs. (5b) and (18) to give

$$
\frac{d r_{0}}{d t}=-\xi^{-1 / 3} \frac{f(\xi)^{-1}}{r_{0} \rho_{s}} m\left\{\frac{(\gamma-1)}{2} \text { e } \frac{\left\langle L\left(E_{e}\right)\right\rangle}{m} J_{e}\right\}^{1 / 3} \int_{E_{e o}}^{E_{e}} \frac{d E_{e}}{L\left(E_{e}\right)}
$$

The extent to which this expression depends on $\xi$ is found by examining the function $\xi^{-1 / 3} f(\xi)^{-1}$ in Fig. 5. The relative constancy of this parameter suggests that the scaling law for pellet ablation will be insensitive to the type of plasma. Table 1 summarizes the discrete values of $\xi^{-1 / 3} f(\xi)^{-1}$ for $\xi$ varying between 10 and 1000. One interesting result is that the coefficlent of the ablaliun rate will be smaller for the dense, hotter plasmas ( $\xi$ large). This is a consequence of the fact that heating confines the gas near the pellet surface for a longer period of time, as evidenced by the strong decrease in $M_{0}$. This effect, although small, could tend to relieve fueling requirements for reactor plàsmàs.

Táking 1.25 as a typical value for the expression $\xi^{-1 / 3} f(\xi)^{-1}$, Eq. (20) can be rewrịtten as

$$
\frac{d r_{0}}{d t}=-0.5 \frac{m}{\rho_{s}} \cdot\left(\frac{e}{m_{e}}\right)^{1 / 6}\left(\frac{e}{m}\right)^{1 / 3} L\left(E_{e \infty} / 2\right)^{l / 3} r_{0}^{-2 / 3} n_{e^{\infty}}^{1 / 3}\left(E_{e \infty}\right)^{l / 6} \int_{E_{e o}}^{E_{e \infty}} \frac{d E_{e}}{L\left(E_{e}\right)}
$$


Using the approximate analytical form for the loss function (see Fig. 2), the integral reduces to the simple result

$$
\int_{E_{e 0}}^{E_{e \infty}} \frac{d E_{e}}{L\left(E_{e}\right)}=\left.\left\{2.35 \times 10^{18} E_{e}+2 \times 10^{15} E_{e}^{2}-\frac{2 \times 10^{21}}{E_{e}}\right\}\right|_{E_{e o}} ^{E_{e}}
$$

where

$$
L\left(E_{e}\right)=\left\{2.35 \times 10^{18}+4 \times 10^{15} E_{e}+\frac{2 \times 10^{21}}{E_{e}^{2}}\right\}^{-1}
$$

Equation (21) is the companion to Eq. (6) and together they form a set that completely determines the ablation rate $d r_{0} / d t$. By itself, Eq. (21) is a purely mechanical constraint that is to be interpreted as an expression for the amount of material that the pellet must expel in order to slow penetrating electrons down to an arbitrary energy $E_{e o}$. For this reason, we refer to it as the equation of the shield, realizing that it assumes significance only when combined with the energy conservation statement of Eq. (6).

Table 1. Values of the coefficient $\xi^{-1 / 3} f(\xi)^{-1}$

$$
\xi \quad f(\xi) \quad \varepsilon^{-1 / 3} f(\xi)^{-1}
$$

10

0.288

1.61

100

0.155

1000

0.081

1.23 
THIS PAGE

\section{WAS INTENTIONALLY \\ LEFT BLANK}




\section{THE DYNAMICS OF THE ABLATION PROCESS}

\subsection{THE GENERALIZED ABLATION RATE EQUATION}

We are in a position now to formulate the pellet ablation process in terms of the results of the preceding sections. The problem is reduced to solving the following set of algebraic and ordinary differential equations:

$$
\begin{gathered}
\frac{d r_{0}}{d t}=-\frac{7.43 \times 10^{-25}}{r_{0}^{2 / 3}} \frac{n_{e^{\infty}}^{1 / 3}}{M^{1 / 3}} E_{e^{\infty}}^{1 / 6}\left[L\left(E_{e^{\infty}} / 2\right)\right]^{1 / 3} \int_{E_{e o}}^{E_{e^{\infty}}} \frac{d E_{e}}{L\left(E_{e}\right)} \\
\frac{d r_{0}}{d t}=-3.7 \times 10^{-22} n_{e^{\infty}} E_{e^{\infty}}^{1 / 2} E_{e o}
\end{gathered}
$$

with

$$
\begin{gathered}
\int_{E_{e 0}}^{E_{e \infty}} \frac{d E_{e}}{L\left(E_{e}\right)}=\left.\left\{2.35 \times 10^{18} E_{e}+2 \times 10^{15} E_{e}^{2}-\frac{2 \times 10^{21}}{E_{e}}\right\}\right|_{E_{e 0}} ^{E_{e \infty}} \\
L\left(E_{e^{\infty}} / 2\right)=\left\{2.35 \times 10^{18}+2 \times 10^{15} E_{e^{\infty}}+\frac{8 \times 10^{21}}{E_{e^{\infty}}^{2}}\right\}^{-1} .
\end{gathered}
$$

To arrive at these expressions we have taken as constants the volumetric latent heat and solid number density of the hydrogen isotopes $\left(\rho_{s} \lambda=2.46 \times 10^{26} \mathrm{eV} / \mathrm{m}^{3}, \rho_{\mathrm{s}} / m=2.32 \times 10^{28} / \mathrm{m}^{3}\right)$. In Eq. $(24), \mathrm{M}$ represents the molecular weight of the fuel which can be any of the pure isotopes or their mixtures.

Equations (24)-(27) are completely general and can be integrated to give the temporal behavior of the pellet radius (and hence fueling rate) even when the plasma parameters are not constant, as in the case of a pellet moving through a nonuniform plasma (or tokamak). Before considering such cases, we first investigate the nature of the solutions for a uniform plasma in order to determine the sensitivity of the ablation rate to the physical parameters. 


\subsection{IMPLICATIONS OF THE SHIELD}

To demonstrate the effectiveness of the shield, Eqs. (24) and (25) are compared in Fig. 6 for the typical conditions $r_{0}=0.5 \mathrm{~mm}$, $n_{e^{\infty}}=5 \times 10^{19} / \mathrm{m}^{3}$, and $E_{e^{\infty}}=1.5 \mathrm{keV}$. Close examination reveals some important features of the model. First, the shield equation [Eq. (24)] rapidly saturates at a near-constant level as the surface energy $E_{\text {eo }}$ drops below several hundred electron volts. The reason for this is obvious if one considers the nature of a shielding process. At $300 \mathrm{eV}$ the electrons have already lost $80 \%$ of their initial energy. It takes only a small additional increase in shield thickness and hence in $\mathrm{dr} / \mathrm{dt}$ to further degrade this energy. The fact that the loss function $L\left(E_{e}\right)$ is large at lower energies also contributes to this effect. This phenomenon is characteristic of plasmas having energies above several hundred electron volts.

It is also evident that the energy equation [Eq. (25)] predicts values of $d r_{0} / d t$ that are far greater than those of the shield equation for surface energies above a few tens of electron volts. This is simply due to the fact that the latent heat of hydrogen, $\lambda$, is small. This point graphically illustrates the importance of the shield in limiting the evaporation rate, for the solution corresponding to a bare pellet [Eq. (25) with $E_{e o}=E_{e_{m}}$ ] exceeds the shielded pellet solution by more than two orders of magnitude.

There is one consequence of this imbalance that is convenient from the point of view of simplicity of computation. For practical size pellets, the solution to the above system of equations almost always occurs at low surface energy (say on the order of $10 \mathrm{eV}$ ) where the sensitivity of Eq. (24) to $E_{e o}$ is small. In essence, this means that Eq. (25) can be disregarded and that the ablation rate can be calculated from Eq. (24) alone with $E_{e o} \approx 10 \mathrm{eV}$. It further implies that the solution will not be proportional to the first power of the plasma density as implied by Eq. (25) but will vary according to the one-third power indicated in Eq. (24). One other closely related consequence is that the ablation rate is not proportional to the plasma power flux. These statements will be valid as long as the density is not so low as to 


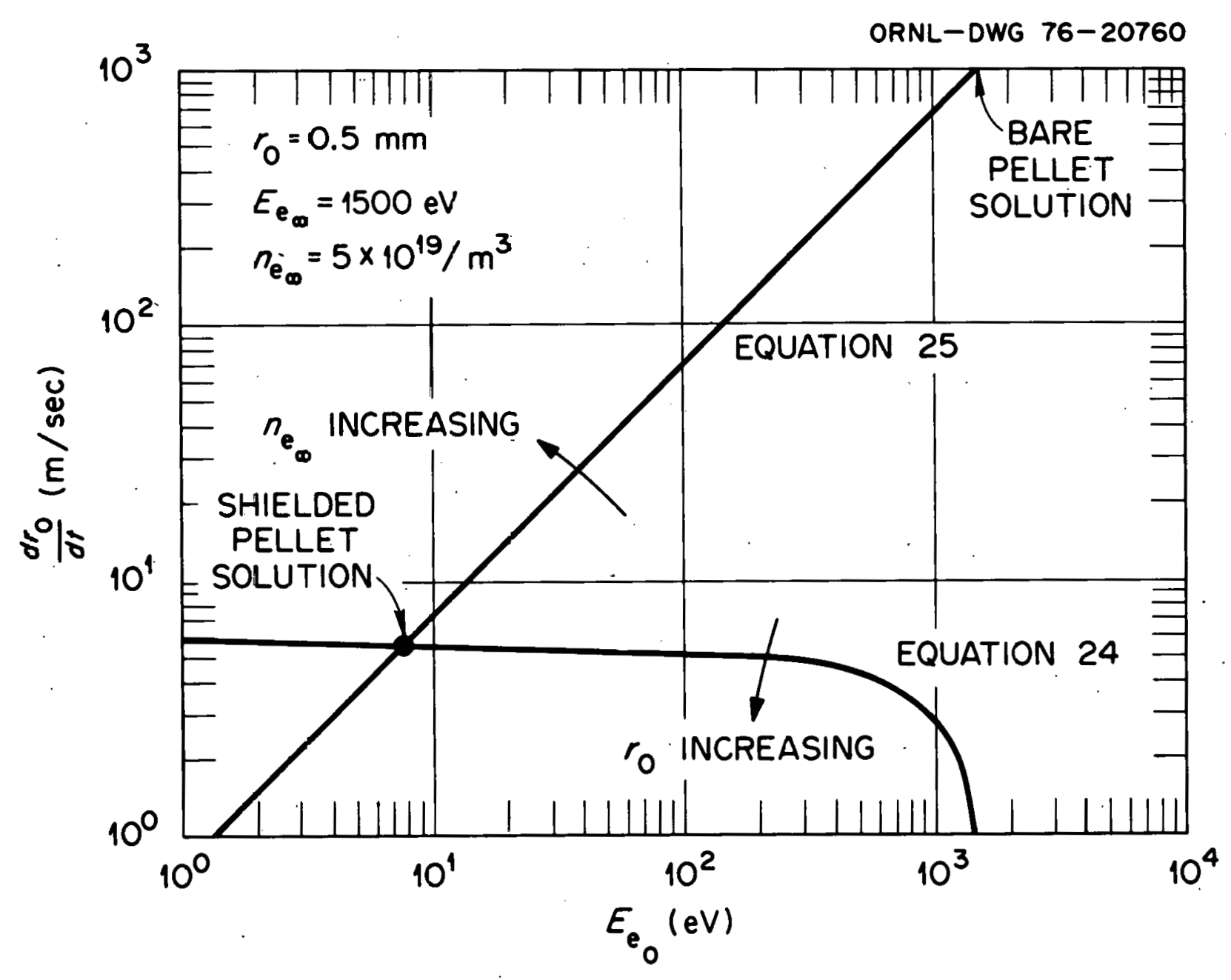

Fig. 6. Comparison of Eqs. (24) and (25) for typical conditions. 
shift the curve describing Eq. (25) to the point where it intersects Eq. (24) in the nonconstant regime. This condition is met for all plasmas of interest.

\subsection{APPROXIMATE PELLET LIFETIME SCALING LAW}

These considerations lead to an approximate pellet lifetime scaling law that is valid for the hotter regions of the plasma (where the significant ablation occurs). Taking $10 \mathrm{eV}$ as a suitable value for $\mathrm{E}_{\mathrm{eo}}$, Eq. (24) becomes

$$
\begin{gathered}
\frac{d r_{0}}{d t} \cong-\frac{1.75 \times 10^{-6}}{r_{0}^{2 / 3}} \frac{n_{e^{\infty}}^{1 / 3}}{M^{1 / 3}} E_{e^{\infty}}^{1 / 6} L\left(E_{e^{\infty}} / 2\right)^{1 / 3} \\
\quad\left\{E_{e_{\infty}^{\infty}}+8.5 \times 10^{-4} E_{e^{\infty} \infty}^{2}-\frac{850}{E_{e_{\infty}}}+75\right\}
\end{gathered}
$$

Concentrating for the moment on the high temperature plasmas for which the energy expressions can be simplified, we can integrate the above result to give the simple pellet lifetime scaling law

$$
r=5.1 \times 10^{13} r_{p}^{5 / 3} M^{1 / 3}\left[_{e^{\infty}}^{-11 / 6} n_{e^{\infty}}^{-1 / 3}\right.
$$

where $r_{p}$ is the initial pellet radius.

Apart from the numerical constant, this is essentially the result obtained by Parks et al. It demonstrates the effectiveness of the shield by the fact that the initial radius appears as the five-thirds power and not linearly. The reason for this nonlinear behavior is that as pellets become smaller, they behave more like point sources of mass for which the shielding clouds dissipate more rapidly in space and become less effective.

The lifetime is most sensitive to electron temperature and this makes hotter plasmas more difficult to fuel. The dependence on density is small, as is the molecular weight. However, higher molecular weight 
fuel, DT for example, will prove somewhat easier to inject. These topics are treated in more detail in Sect. 5, in which tokamak fueling requirements are discussed.

Before leaving this subject, we consider the effect of varying pellet size on the effectiveness of the shield. Figure 6 shows that the solution for a shielded pellet will begin to approach that of the unshielded or bare pellet when the curve representing Eq. (24) is displaced upward by a few orders of magnitude. According to Eq. (24), this would occur if the pellet were reduced in size by a correspondingly somewhat larger factor. The resulting pellet size would be on the order of $5 \mu \mathrm{m}$ or less. This is the approximate range of pellet size below which the neutral gas shield is rende'ed ineffectual. Fueling schemes involving such small pellets might necessarily have to rely on extremely high velocities to fuel the interior of hot plasmas. 
THIS PAGE

WAS INTENTIONALLY

LEFT BLANK 


\section{COMPARISON WITH ORMAK EXPERIMENTS}

\section{1 EXPERIMENTAL RESULTS AND PLASMA CONDITIONS}

Recent experiments were conducted on ORMAK ${ }^{4}$ which provide an opportunity for experimental verification of the model. Frozen hydrogen pellets of 210-u-diam nominal size were injected into the edge plasma at speeds of approximately $100 \mathrm{~m} / \mathrm{sec}$ along a trajectory that made an angle of $45^{\circ}$ with respect to the tangent to the plasma liner. A photomultiplier tube mounted on the injection port (neutral beam line) and used to monitor $H_{\alpha}$ light emitted from the ablation cloud served as the primary diagnostic for observing the pellet-plasma interaction. In addition to these measurements, a high speed framing camera was employed to give direct visual evidence of the ablation process. Relevant plasma parameters for the series of runs were obtained from ORMAK diagnostics, including laser (Thomson) scattering for the electron temperature, microwave interferometry for electron density (line average), and the double Langmuir probe for both electron temperature and density within the shadow of the limiter. Plasma current and toroidal magnetic field were $60 \mathrm{kA}$ and $12 \mathrm{kG}$, respectively. A schematic of the experiment is presented in Fig. 7 .

Typical signals obtained from the $\mathrm{H}_{\alpha}$ monitor are shown in the series of oscillographs presented in Fig. 8. The trace labeled A represents the emitted light record from initiation of the discharge through completion of the shot. Individual pellets are identified by the series of sharp light bursts beginning at about $30 \mathrm{msec}$. The large, uniform bursts of light occurring later in the discharge (40-55 msec) are ful1size pellets, as opposed to the smaller signals, which are pellet fragments. Pellets were formed partially frozen and were rapidly accelerated by a gasdynamic technique 5 wich would explain the formation of fragments and late arrival of the larger pellets. The trace labeled $B$ represents a 10-msec expanded section of the emitted light record concentrating on the time interval when whole pellets arrive at the plasma. The important feature to observe is the characteristic manner in which the luminosity increases rapidly and then decreases abruptly to extinction in less than a millisecond. This means that after entering the plasma, pellets travel at most $10 \mathrm{~cm}$ along the beam line, which corresponds to a radial position 


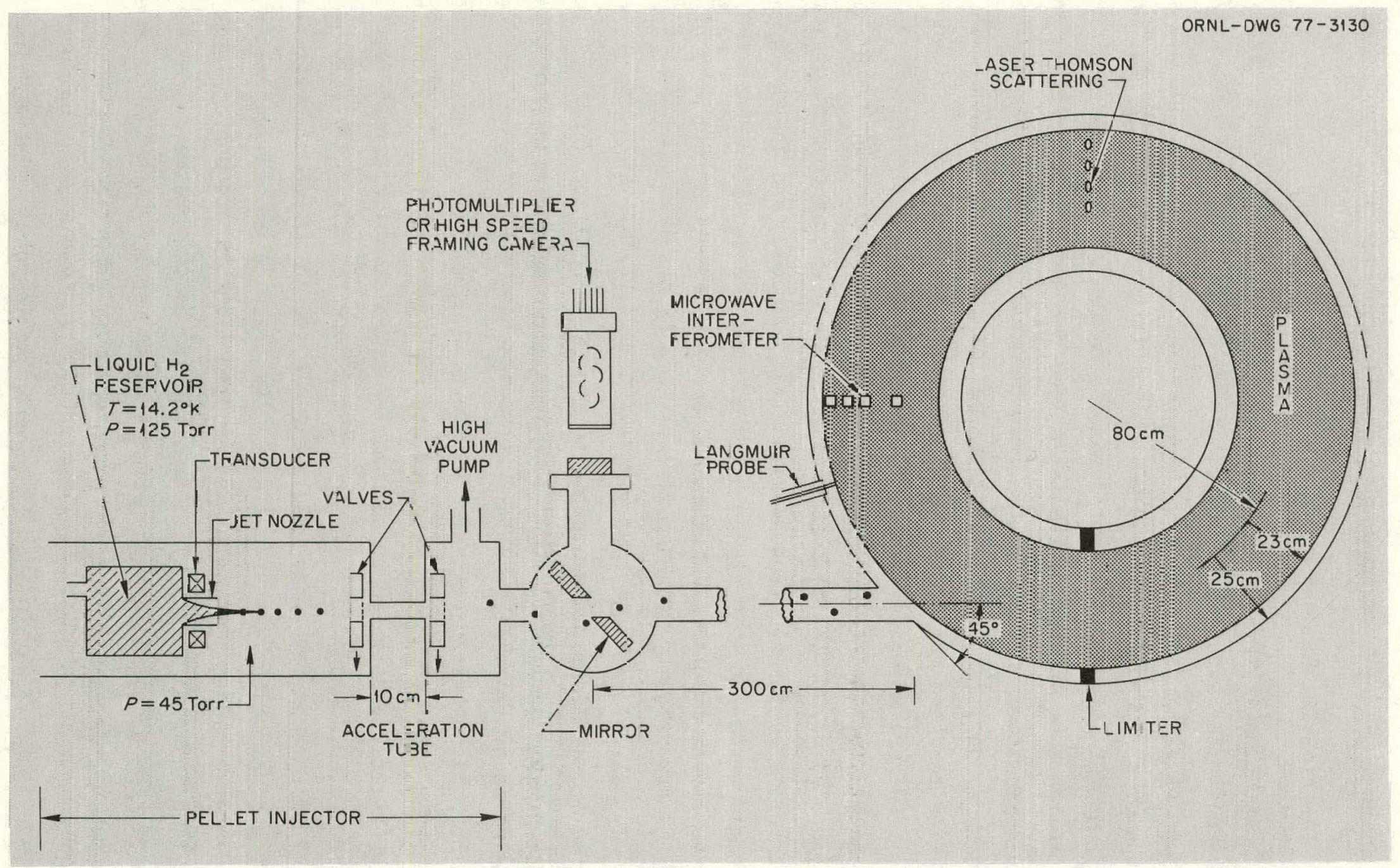

Fig. 7. Schematic of experimental arrangenent for jellet injection studies on ORMAK featuring University of Illino's pellet apparatus. 
ORNL-DWG 77-3704
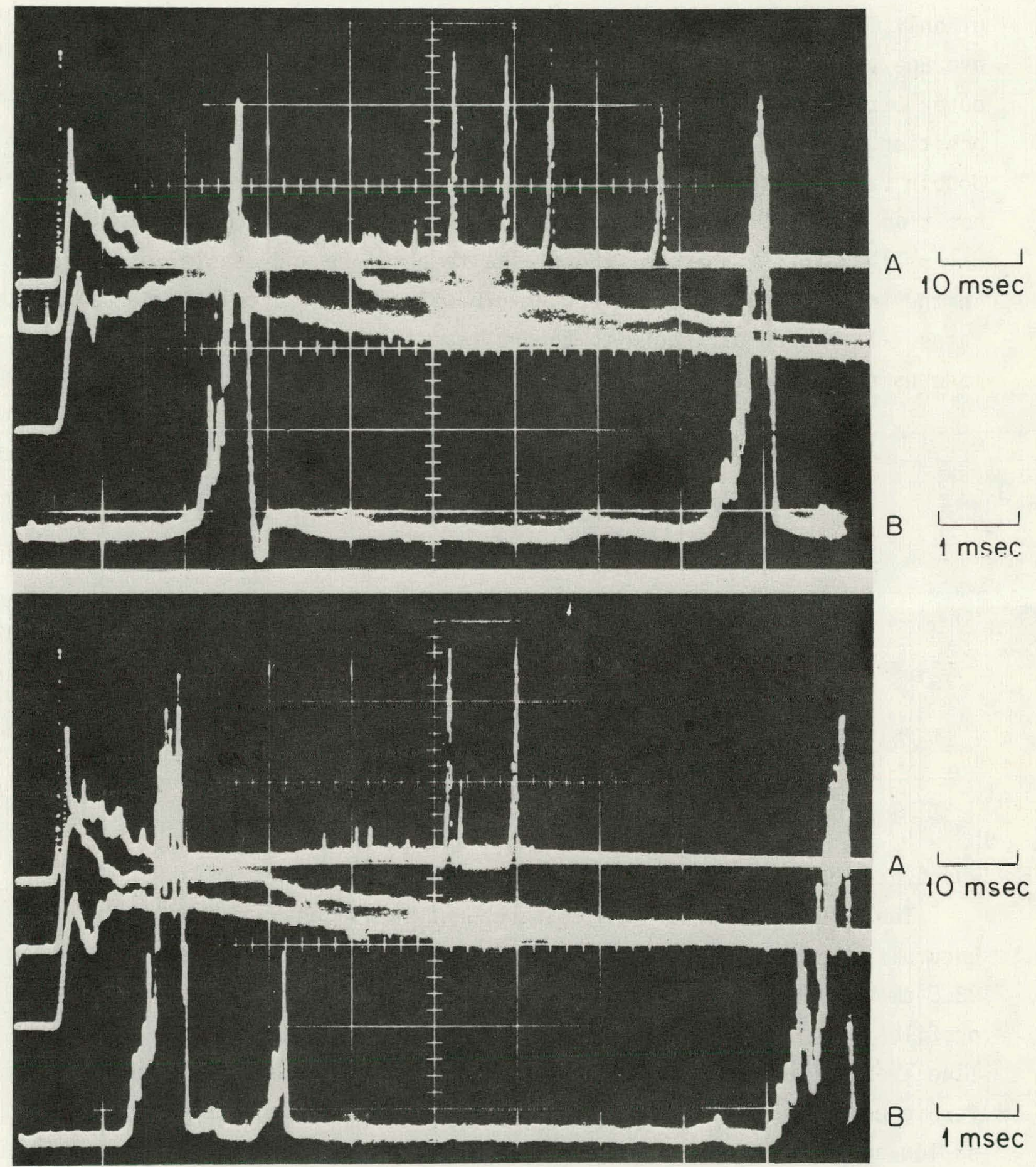

Fig. 8. Experimental $\mathrm{H}_{\alpha}$ records of pellet-plasma interaction depicting plasma luminosity during pellet injection. 
of $18 \mathrm{~cm}$ at the point of extinction. This is still within the region defined as the plasma edge where electron temperatures are on the order of only $100 \mathrm{eV}$ and plasma density levels are only about $20 \%$ of their 1 ine average values. The plasma is not well defined in this region - the outermost laser Thomson scattering station is located at the $15.6-\mathrm{cm}$ position. The only other relevant diagnostic in the vicinity is the double Langmuir probe which measures density and temperature at the $23.5-\mathrm{cm}$ position just within the shadow of the limiter. This introduces some uncertainty in the shape of the plasma tempcrature and density profiles in the intervening region which in turn affects the calculated ablation rates. In the comparison with theory that follows, calculations werc made using the following spatial temperature and density profiles:

$$
\left.\begin{array}{l}
T_{e_{\infty}^{\infty}}(e V)=125\left(1-\frac{r}{0.25}\right) \\
n_{e^{\infty}}=2.5 \times 10^{18}\left(1-\frac{r}{0.25}\right)
\end{array}\right\} 0.23 \leq r \leq 0.25 \mathrm{III}
$$

where $r$ is the plasma radius.

The piecewise linear temperature profile is consistent with the Langmuir probe and 1aser Thomson scattering measuremenls made at the $23.5-\mathrm{cm}$ and $15.6-\mathrm{cm}$ positions, respectively. The assumed density profiles dre in agreement with the Langmuir probe data and satisfy the line average value $\left(\sim 1 \times 10^{19} \mathrm{~m}^{-1}\right)$ obtained from the microwave interferometer measurements. The three-halves power law dependence is typical of low current ORMAK discharges. ${ }^{6}$ Calculations were also made with differently shaped, but consistent, profiles to test the sensitivity of the model to this parameter. 


\subsection{REVISED ABLATION RATE EQUATION}

The fact that pellets did not penetrate beyond the plasma edge affects the ablation rate calculation in another way; namely, the parameter $\xi$ introduced in Sect. 2.2 is likely to have a smaller value indicative of the weaker plasma. As shown in Fig. 5, this results in larger values of the parameter. $\left[\xi^{-1 / 3} f(\xi)^{-1}\right]$ than were chosen in deriving Eq. (21). The higher ablation rates result from the absence of strong heating in the ablation cloud. As discussed earlier, heating. produces a desired "bottling" of the flow at the pellet surface which enhances the effectiveness of the shield. The extent to which this modifies the result of Eq. (21) can be determined by evaluating Eq. (16) for the mean ORMAK plasma conditions encountered by the pellet, i.e., $E_{e \infty}=50 \mathrm{eV}, n_{e^{\infty}}=3 \times 10^{18} \mathrm{~m}^{-3}, r_{0}=1.05 \times 10^{-4} \mathrm{~m}$. A characteristic value of 10 results for $\xi$ and (from Fig. 5) the parameter $\xi^{-1 / 3} f(\xi)^{-1}$ is increased to 1.6 as compared to 1.2 used earlier for the hot plasma case. Taking this into account and rewriting Eqs. (24) and (25) in terms of the rate at which neutral atoms are added to the plasma (in the form of molecules) we arrive at the following equivalent expressions for the ablation rate:

$$
\begin{aligned}
\frac{d N}{d t} & =\frac{2 p_{s}}{m} 4 \pi r_{n}^{2} \cdot \frac{d r_{0}}{d t} \\
& =5.58 \times 10^{5} \frac{{ }_{e^{\infty}}^{1 / 3}}{m^{1 / 3}} E_{e^{\infty}}^{1 / 6} r_{0}^{4 / 3} L\left(E_{e \infty} / 2\right)^{1 / 3} \int_{E_{e o}}^{E_{e \infty}} \frac{d E_{e}}{L\left(E_{e}\right)}
\end{aligned}
$$

and

$$
\frac{d N}{d t}=2.16 \times 10^{8} r_{0}^{2} n_{e^{\infty}} E_{e^{\infty}}^{1 / 2} E_{e o}
$$

with $L\left(E_{e}\right)$ as defined previously. 
In the discussion that follows, the total observed luminosity of the cloud is interpreted as being proportional to the rate at which the pellet surface supplies neutrals to the plasma; hence the above result is to be compared with the observed $H_{\alpha}$ signal. Specifically, the constant of proportionality is given in terms of the integrated light signal as

$$
\frac{d N}{d t}=C S
$$

with

$$
C=\frac{\frac{8}{3} \pi \frac{\rho s}{m} r_{p}{ }^{3}}{\int s d t}
$$

where $r_{p}$ is the initial pellet radius and $S$ is the instantaneous light signal. The quantity in the numerator of Eq. (33) is simply the total number of neutral atoms within a pellet of radius $r_{p}$.

\section{3 COMPARISON WITH EXPERIMENT}

Numerical solutions of Eqs. (30) and (31) were obtained for the approximate conditions under which the experiments were performed using the plasma conditions and pellet trajectory information discussed in Sect. 4.1 as input. The comparison with experiment is shown in Fig. 9 where the data for three similar shots have been assembled to form a composite of the ablation process. As concerns the pellet lifetime and the general shape of the ablation curve, the agreement is good. The initial rapid rise in ablation rate is a distinct feature of the experimental results which the theory does not reproduce. One possible explanation for this discrepancy is that the temperature and/ur density at the plasma edge is somewhat higher than the values used in the calculation. An increase by a factor of two in both temperature and density at the limiter edge would be sufficient to raise the initial part of the theoretical curve to the level of the experimental observations, and these new plasma conditions would still be within the range indicated by the Langmuir probe measurements. The assumed plasma profiles could 


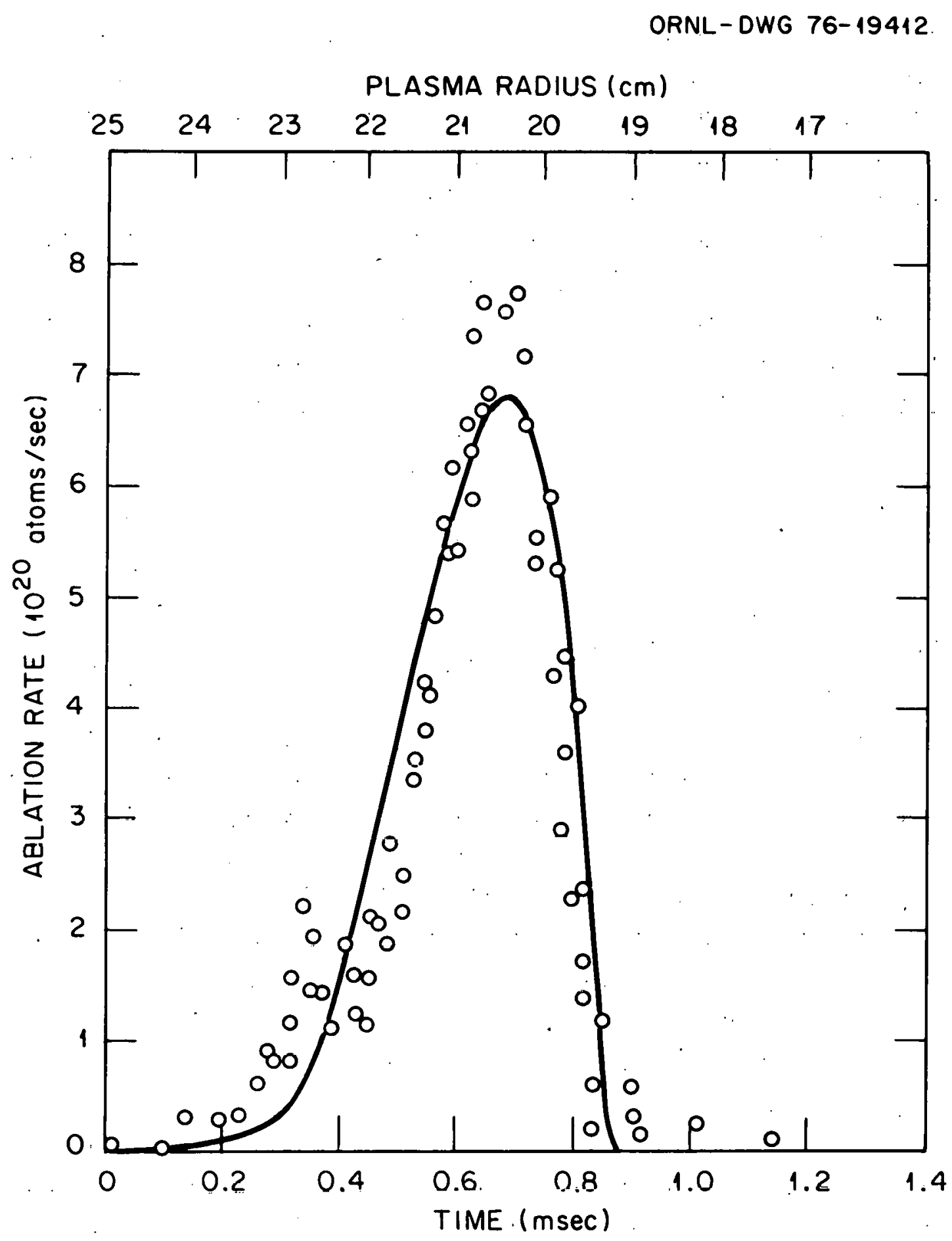

Fig. 9. Three-shot composite of ablation rate inferred from $\ddot{H}_{\alpha}$ data. Solid line represents neutral gas shielding model calculation for 210-um-diam pellet. 
also be somewhat in error since detailed information at the plasma edge is presently not available. The uncertainty in plasma position with respect to the liner might also be a contributing factor. In this regard, it is interesting to note that the location of the initial burst of light corresponds roughly to the point at which the pellet emerges from the shadow of the limiter.

Further evidence of the agreement between the model and experiment is provided by the sequence of photographs shown in Fig. 10 depicting the time evolution of the luminous ablation cloud of a single pellet. Each photograph represents a 50-usec time exposure and the interval between events is $140 \mu \mathrm{sec}$. The total elapsed time is $700 \mu \mathrm{sec}$; but, given that the time resolution is $1.40 \mu \mathrm{sec}$, the appropriate pellet lifetime is $840 \mathrm{\mu sec}$, which is in excellent agreement with the calculated value of $850 \mu \mathrm{sec}$.

The photographs provide additional quantitative information, including the size of the luminous cloud and the relative luminosity of individual frames. The latter is subject to direct comparison with the $\mathrm{H}_{\alpha}$ signals and hence, through the normalization procedure, with the ablaliun rate calculation. At its greatest size and intensity, the cloud is approximately $3 \mathrm{~cm}$ wide, which is more than twn orders of magnitude greater than the physical dimensions of the pellet. The development of the luminous cloud is best illustrated by the sequence of profiles shown in Fig. 11, depicting the spatial variation of the optical density of the cloud images. The densitometer readings were taken by sweeping a narrow slit across the individual images. The area under each proftle is proportional to the instantaneous value of the luminosity or the cloud and, to be consistent, the development in time should parallel the $\mathrm{H}_{\alpha}$ record. Figure 12 demonstrates the agreement between these two observations by comparing the processed photographic information with the theoretical profile. The agreement is as good as that obtained in the comparison with the $H_{\alpha}$ results and the same trends are apparent, at least to within the time resolution of the photographic experiment. The conclusion is that the two measurements are equivalent. 


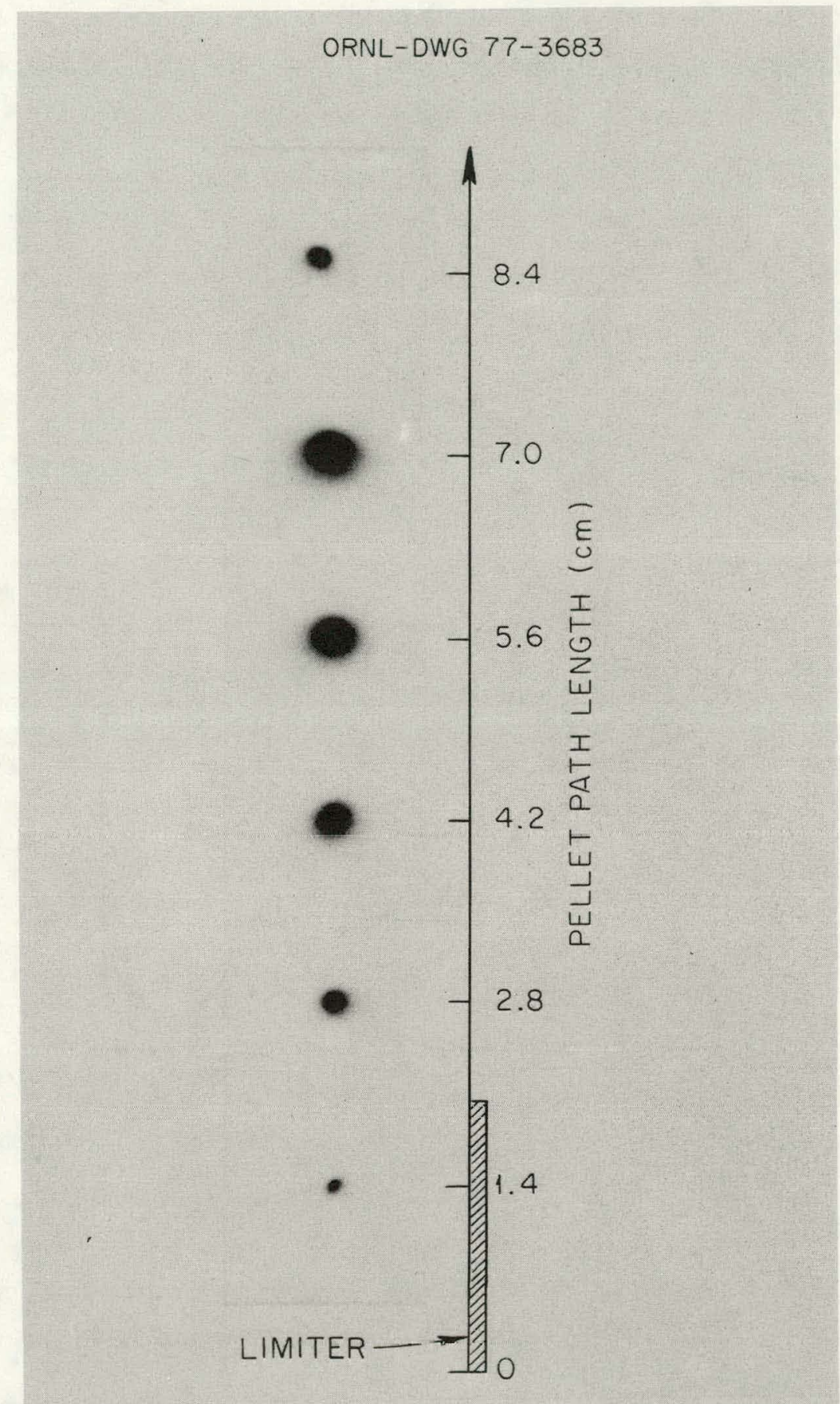

Fig. 10. High speed framing camera photographs depicting evolution of luminous cloud of a single pellet. Time between frames is $140 \mu \mathrm{sec}$. 


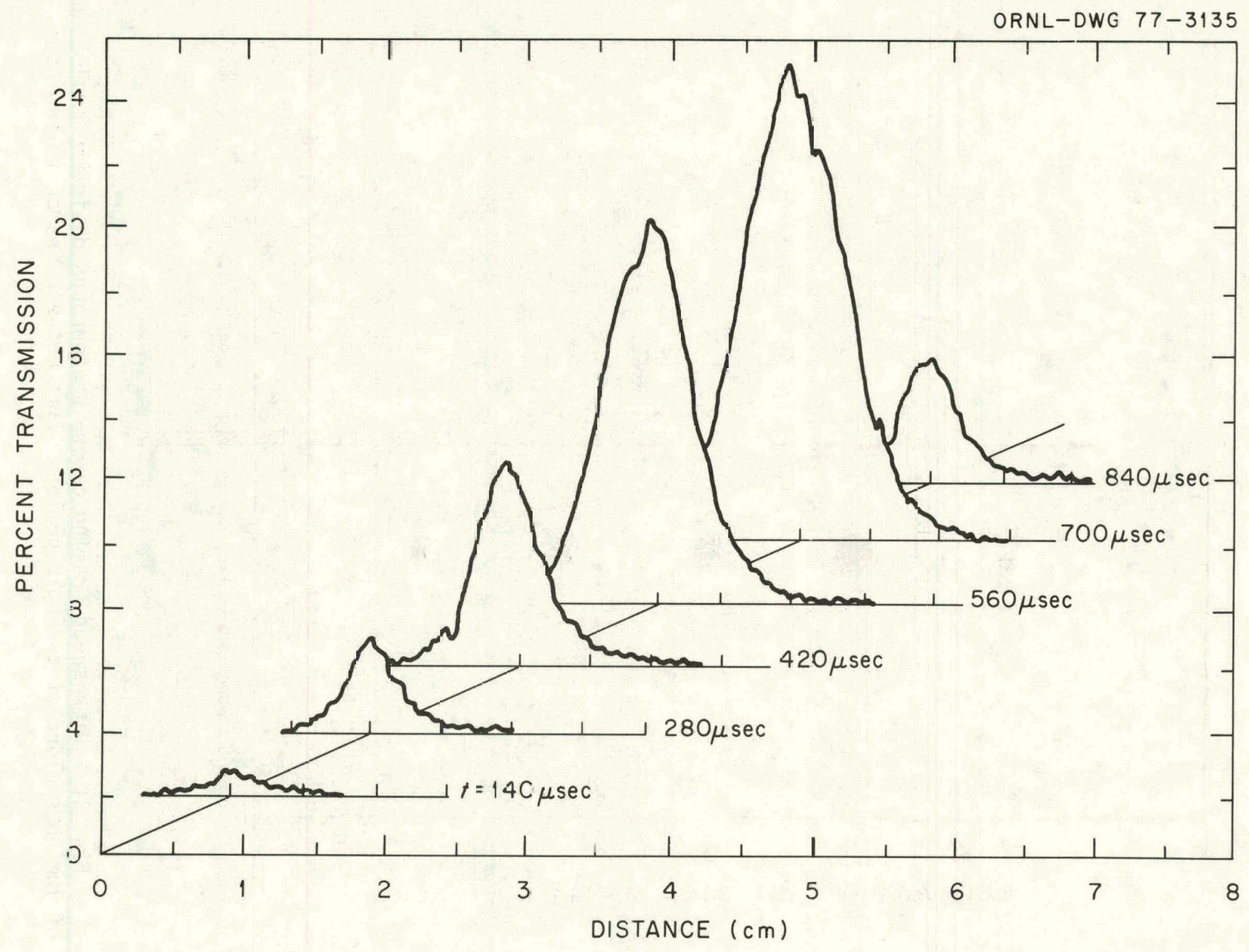

Fig. 11. Densitometer scans of images shown in Fig. 11)-dimensions are full scale. 


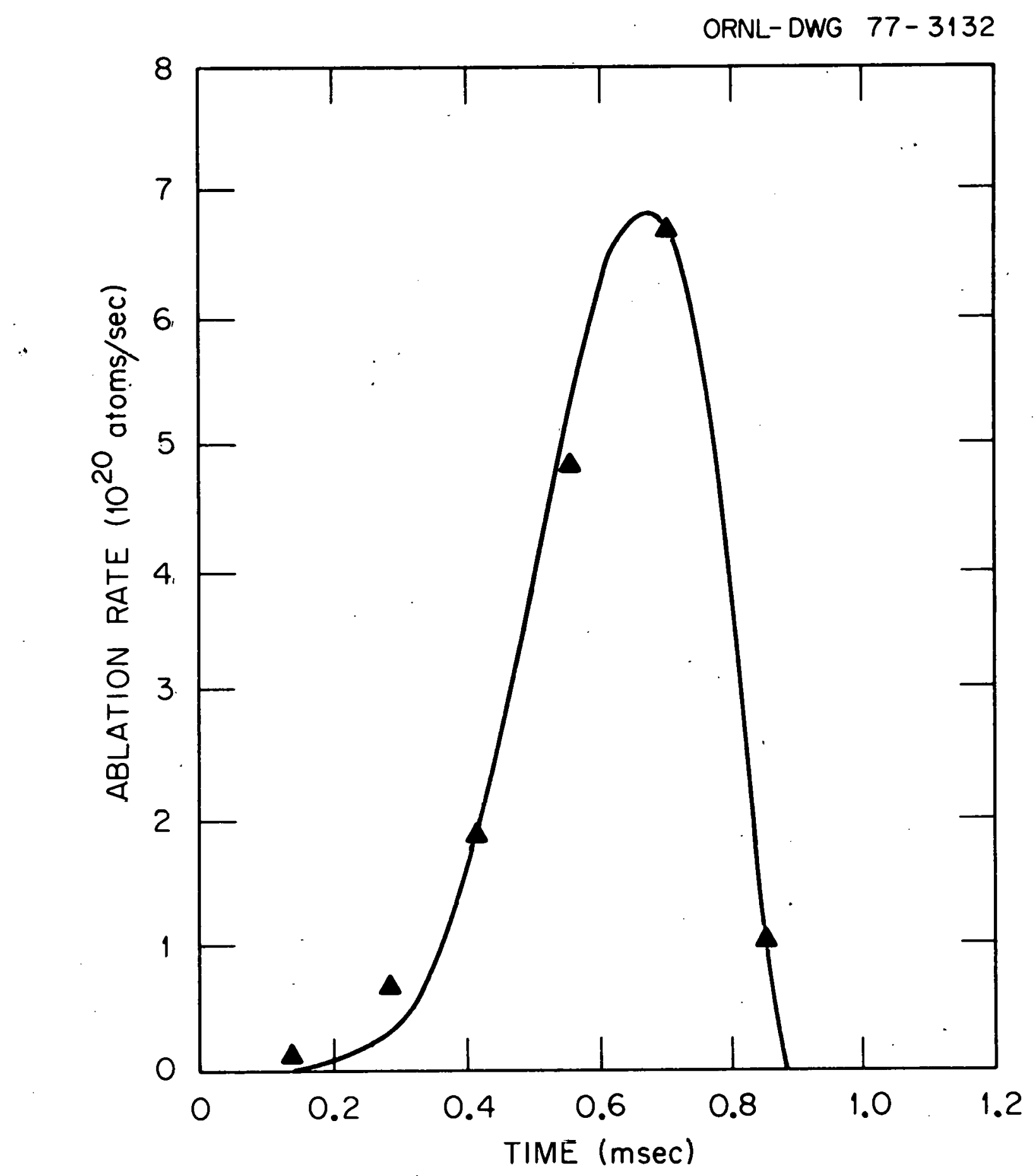

Fig. 12. Ablation rate inferred from the sequence of densitometer scans of Fig. 11. Solid line represents neutral gas shielding model calculations for 210- $\mu \mathrm{m}$-diam pellet. . 
Finally, we consider the sensitivity of the model to variations in the shape of the electron density profiles, since the exact profile is unknown. Calculated results are shown in Fig. 13 for three density profiles that are consistent with the measured line average value. The plasma between the liner and limiter edge for all three cases (0-0.3 msec) is unchanged, but the plasma within the main discharge varies according to the indicated power laws. The more steeply rising profiles give rise to more rapid evaporation and slightly shorter lifetimes although the dependence is less than linear, as indicated by the form of Eqs. (30) and (31). All three profiles could be said to give gond agreement with the data, but the preferred profile (three-halves power) best represents the overall observed results. 


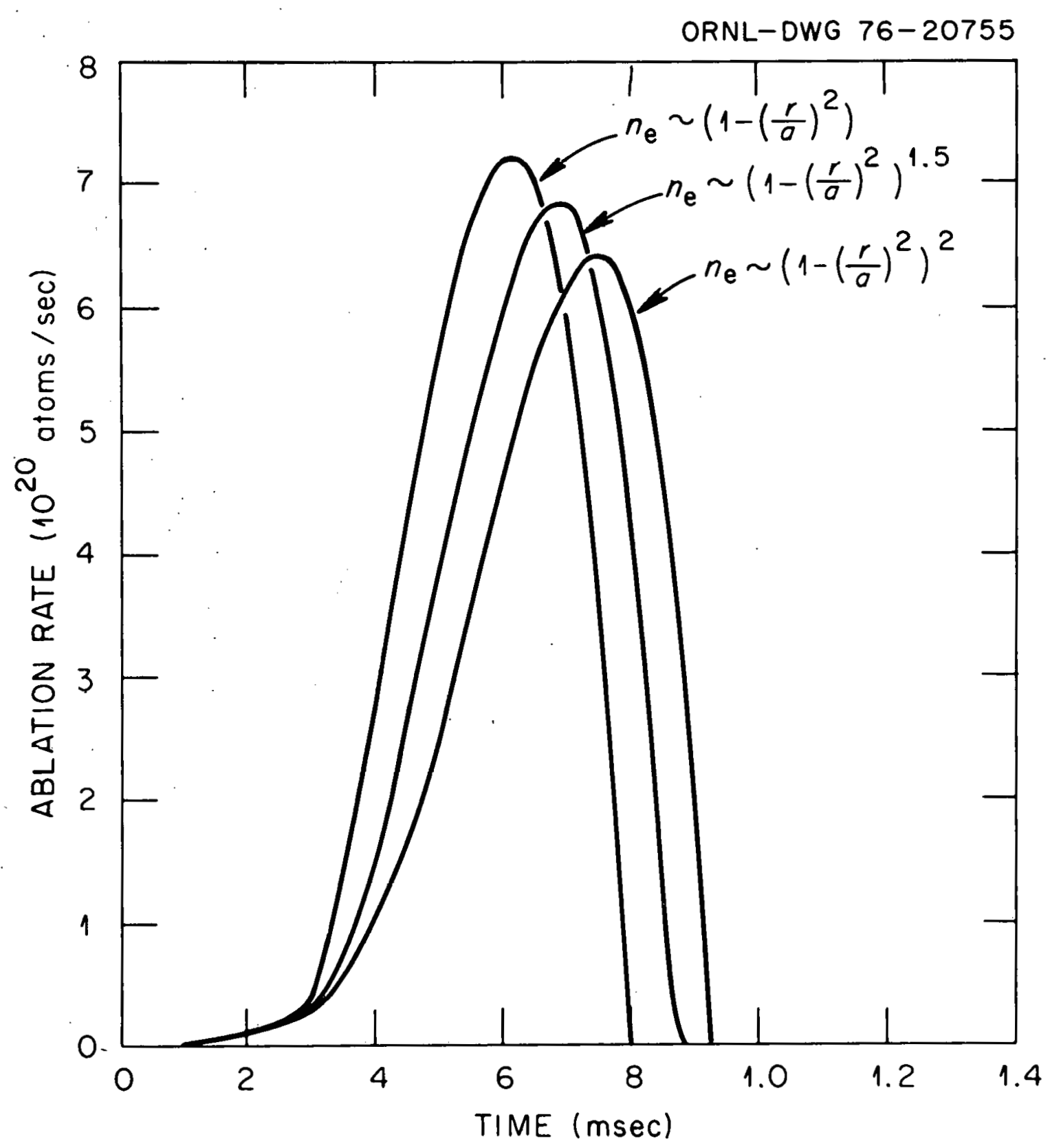

Fig. 13. Calculated ablation rates for different electron density profiles. Pellet diameter $=210 \mu \mathrm{m}$. 


\section{THIS PAGE}

WAS INTENTIONALLY

LEFT BLANK 


\section{PELLET FUELING APPARATUS DESIGN CONSIDERATIONS}

\section{1 PELLET VELOCITY SCALING LAW}

The relative simplicity of the model and the demonstrated agreement with experiment are reasons for further exploring the model's predictive capabilities as a tool for estimating tokamak fueling parameters, although some caution should be used in interpreting the results of such an exercise since additional experimental verification on hot, dense plasmas is needed. With regard to design of plasma fueling devices, it is appropriate to consider first the question of how far a pellet of a : certain size would penetrate in a given plasma and what injection velocity would be required to achieve a desired depth of penetration. This information can be obtained by solving the system of equations in Sect. 3.1 for given time-dependent plasma properties as determined by the temperature and density profile and the assumed pellet trajectory. A less direct but more meaningful exercise is to integrate the approximate ablation rate expression given by Eq. 28 between the time the pellet enters the plasma and the time it anishes. The velocity is introduced into the analysis by replacing the time derivative with the convective derivative which, for perpendicular injection, reduces to $d t=-d r / U$, where $r$ is the plasma radius and $U$ is the pellet speed. A useful scaling law results when similar plasma profiles are considered; for the purposes of this analysis, the following profiles are assumed (for circular plasmas):

$$
E_{e_{\infty}}=\frac{3}{2} T_{e^{\infty}}=\frac{45}{16}\left\langle T_{e^{\infty}}\right\rangle\left[1-(r / a)^{2}\right]^{2}
$$

and

$$
n_{e_{\infty}}=\frac{3}{2}\left\langle n_{e_{\infty}}\right\rangle\left[1-(r / a)^{2}\right]
$$

where the bracketed quantities represent simple plasma average values and $a$ is the plasma minor radius. 
By integrating over the lifetime of the pellet $\left(0 \leq r_{0} \leq r_{p}\right)$, Eq. (28) reduces to the following expression

$$
\begin{array}{r}
U r_{p}^{5 / 3}=\frac{2.92 \times 10^{-6} a}{M^{1 / 3}} \int_{\ell / a}^{1} L\left(E_{e^{\infty}} / 2\right)^{1 / 3} n_{e_{\infty}^{\infty}}^{1 / 3} E_{e_{\infty}^{\infty}}^{1 / 6} \\
\left\{E_{e_{\infty}}+8.5 \times 10^{-4} E_{e^{\infty}}{ }^{2}-\frac{850}{E_{e_{\infty}}}+75\right\} d(r / a)
\end{array}
$$

where $\ell$ represents the radial position at which the pellet vanishes $\left(r_{0}=0\right)$ and $r_{p}$ is the initial pellet size. The latter can be conveniently expressed in terms of the physical characteristics of the device and the fractional amount of fuel (ions) that the pellet contributes to the plasma. The fraction $f$ is introduced to ensure that perturbations created in the plasma by the introduction of fresh fuel will not be large. It is defined in terms of the plasma volume $V$ and average density by the expression

$$
r_{p}=1.57 \times 10^{-10}(\mathrm{fV})^{1 / 3}\left\langle n_{\mathrm{e}_{\infty}}\right\rangle^{1 / 3}
$$

With this result, the velocity required for penetration to the fractional radial position $\ell / a$ is given finally by

$$
U=\frac{a}{M^{1 / 3}}(f V)^{-5 / 9}\left\langle n_{e_{e s}}\right\rangle^{-2 / 9}\left\langle T_{e^{\infty}}\right\rangle^{1 / 6} G_{i}\left(\left\langle T_{e^{\infty}}\right\rangle ; l / / 9\right)
$$

where the function $G$ is a complicated integral expression given by

$G=\frac{1.84 \times 10^{5}}{\left\langle T_{e^{\infty}}\right\rangle^{1 / 3}} \int_{l / a}^{1} x^{1 / 3} \frac{\left\{x+2.4 \times 10^{-3} x^{2}-10 / . b\right.}{x+26.7\}} d(r / a)$

with

$$
x=\left\langle T_{e \infty}\right\rangle\left[1-\left(\frac{r}{a}\right)^{2}\right]^{2}
$$


The function $G$ is shown in Fig. 14 for several values of the penetration parameter $\ell / a$. The series of curves are only slightly divergent with the dependence on mean plasma temperature varying approximately as the 1.54 power for the central injection case $(l / a=0)$. This means that, over a fairly wide range of conditions, the velocity will scale as $U \sim\left\langle T_{e_{\infty}}\right\rangle^{1.7}$. Also, for the higher temperature plasma, the information of Fig. 14 reveals that $G$, and hence the velocity, varies as the cube of the injection depth $(1-\ell / a)$ for penetration beyond the halfway point. Incorporating these results in Eq. (39) produces the simple velocity scaling law

$$
U \sim a \frac{(f V)^{-5 / 9}}{M^{1 / 3}}\left\langle n_{e_{\infty}}\right\rangle^{-2 / 9}\left\langle T_{e_{\infty}}\right)^{1.7}(1-\ell / a)^{3}
$$

Considering the implied strong dependence on both injection depth and temperature, it is legitimate (for the higher temperature systems) to question whether penetration to the plasma center is essential. Technological difficulties would be greatly relaxed if fueling devices need only provide fuel up to a fraction of the distance from the plasma center. For example, penetration to $\ell / a=0.33$ would bring about a three fold reduction in the velocity needed to attain the plasma's center.

Other factors being constant, Eq. (40) implies that fueling requirements will be relieved as plasma densities increase. The reason for this is the fact that, for constant $f$, higher density plasmas can accommodate larger pellets which exhibit more effective shielding, as pointed out in Sect. 3.3. For the same reasons, higher plasma volume and larger values of the fraction $f$ will also reduce velocities, and for these parameters, the reduction is more pronounced.

For noncircular plasmas, the above results will still be correct if the minor radius, a, is replaced by the distance to the magnetic axis (assuming that the profiles shift accordingly). In this respect, large noncircular and/or shifted plasmas should clearly be favored since the distance, a, may be small in comparison with the equivalent minor radius. 


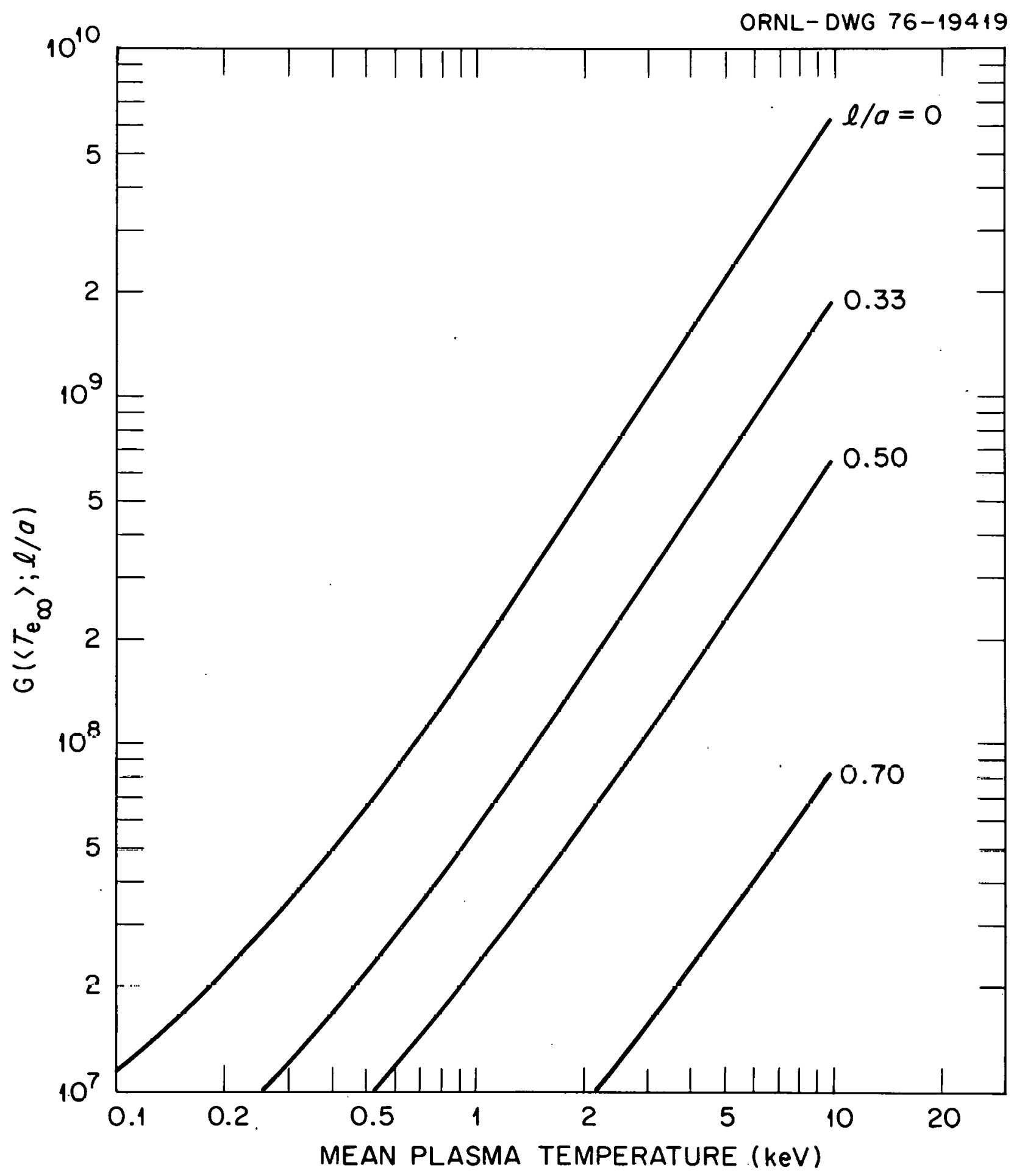

Fig. 14. Dependence of the function G of Eqs. (38)-(39) on mean plasma temperature and fractional distance from the plasma center. 


\subsection{ESTIMATE OF FUELING PARAMETERS FOR MAJOR EXPERIMENTAL DEVICES}

Listed in Table 2 are estimates of fueling parameters for a few present and future tokamak experiments beginning with. ORMAK and progressing up to the proposed D-T ignition device TNS. The velocity projections were made based on the assumed plasma profiles given in the previous section. Pellet radii were chosen so that each pellet contributes $10 \%$ of the device total ion content $(\dot{f}=0.1)$. The velocities given result in pellets penetrating roughly two thirds of the way to the plasma center. In the case of TNS, the fuel is DT ( $M=5$ instead of 2 as in all other examples).

Recalling the results of Sect. 5.1, the projected velocities follow predictable trends. The beam-heated plasmas, by virtue of their higher temperatures, require considerably higher velocities. ORMAK Upgrade with ohmic heating may prove easier to fuel than ISX and ORMAK because of its greater volume and higher anticipated densities. Beamdriven plasmas, in particular TNS, will prove difficult to fuel in the manner chosen. To relieve these requirements it may be necessary to increase the value of $f$ and/or decrease the desired depth of penetration. For example, by allowing each pellet to contribute 15\% of the plasma ion content, the TNS figure would be reduced to $7000 \mathrm{~m} / \mathrm{sec}$. According to Eq. (40), decreasing the desired penetration depth from 0.67 to 0.6 would further reduce the velocity to $5000 \mathrm{~m} / \mathrm{sec}$. Of course, the manner in which fueling is performed would necessarily have to be chosen in accordance with the device operating characteristics.

Although estimates of this nature are often useful, it mus.t be remembered that further experimental verification is needed and these results should be interpreted accordingly. The most important conclusion to be drawn from this exercise is that, since beam-heated devices like PLT and ORMAK Upgrade require injection velocities similar to the ignition device TNS, many of the questions surrounding pellet fueling may be resolved in the next series of experiments. 
Table 2. Estimates of experimental pellet fueling requirements For pellets containing $10 \%$ of device total ion content and for perpendicular injection; parameters are plasma center values; $\ell / a \approx 0.33$

\begin{tabular}{lll} 
& Device & Pellet \\
& $\underline{\text { radius }}$ & \\
\hline
\end{tabular}

\begin{tabular}{|c|c|c|c|c|c|}
\hline & $a(m)$ & $\mathrm{Te}$ (keV) & $n e\left(m^{-3}\right)$ & $\left(10^{-6} \mathrm{~m}\right)$ & $(\mathrm{m} / \mathrm{sec})$ \\
\hline ORMAK & 0.23 & 1.0 & $7 \times 10^{19}$ & 250 & 2500 \\
\hline ISX & 0.25 & 1.0 & $7 \times 10^{19}$ & 285 & 2500 \\
\hline $\begin{array}{l}\text { ORMAK } \\
\text { Upgrade }\end{array}$ & 0.30 & $\begin{array}{l}0.9 \\
3.0 a\end{array}$ & $\begin{array}{l}1 \times 10^{20} \\
1 \times 10^{20}\end{array}$ & $\begin{array}{l}350 \\
350\end{array}$ & $\begin{array}{l}2000 \\
7000\end{array}$ \\
\hline PDX & $0.47 / 0.57$ & $\begin{array}{l}1.0 \\
3.0^{a}\end{array}$ & $\begin{array}{l}3 \times 10^{19} \\
1 \times 10^{20}\end{array}$ & $\begin{array}{l}400 \\
580\end{array}$ & $\begin{array}{l}2000 \\
5000\end{array}$ \\
\hline PLT & 0.45 & $\begin{array}{l}1.7 \\
4.0^{\circ}\end{array}$ & $\begin{array}{l}5 \times 10^{19} \\
1 \times 10^{20}\end{array}$ & $\begin{array}{l}410 \\
510\end{array}$ & $\begin{array}{l}4000 \\
8000\end{array}$ \\
\hline TNS $^{b}$ & $1.25 / 2.0$ & $20.0^{a}$ & $3.3 \times 10^{20}$ & 3000 & 9000 \\
\hline
\end{tabular}

With neutral beams.

bParameters chosen to preserve 1 ine average values. Distance to plasma center $=0.62 \mathrm{~m}$. 
NOMENCLATURE AND UNITS

A Pellet cross section for interception of plasma electrons $\left(\mathrm{m}^{2}\right)$

a Plasma minor radius ( $m$ )

$a_{s}$ Gas sound speed ( $\left.\mathrm{m} / \mathrm{sec}\right)$

C Proportionality factor

$\bar{C}_{e} \quad$ Electron thermal speed $(\mathrm{m} / \mathrm{sec})$

$E_{e} \quad$ Electron energy (eV)

e Elementary charge

$f$ Ratio of pellet ion content to plasma ion content

G Function defined by Equation (39)

h Fluid enthalpy $(\mathrm{J} / \mathrm{Kg})$

I Electron power attenuation factor

$\mathrm{J}$ Electron flux $\left(\mathrm{sec}^{-1} \mathrm{~m}^{-2}\right)$

k Boltzmann's constant

\& Plasma radius at which pellet vanishes ( $m$ )

$L\left(C_{e}\right)$ Electron encrgy loss function (cV $-m^{2}$ )

M Mach number; molecular. weight of ablatant

$m$ Molecular mass of ablatant $(\mathrm{Kg})$

$m_{\mathrm{e}} \quad$ Electron mass $(\mathrm{Kg})$

$\dot{\mathrm{m}}$ Mass flow rate $(\mathrm{Kg} / \mathrm{sec})$

$\frac{\mathrm{dN}}{\mathrm{dt}} \quad$ Rate at which hydrogen neutrals are given off by pellet $\left(\mathrm{sec}^{-1}\right)$

$\mathrm{ne}$ Electron number density $\left(\mathrm{m}^{-3}\right)$

$\mathrm{P} \quad$ Fluid pressure $(\mathrm{Pa})$

Q Electron power incident on pellet surface (watts)

$\dot{q} \quad$ Volumetric heat generation (watts $/ \mathrm{m}^{3}$ ) 
$r \quad$ Pellet system radial coordinate; plasma radius (m)

$r_{0} \quad$ Instantaneous pellet radius $(m)$

$r_{p} \quad$ Initial pellet radius (m)

$\frac{d r_{0}}{d t}$ Pellet ablation rate $(\mathrm{m} / \mathrm{sec})$

S $\quad H_{\alpha}$ signal

$T$ Gas temperature $(K)$

$\mathrm{T}_{\mathrm{p}} \quad$ Electron temperature (eV)

$U$ Pellet injection velocity $(\mathrm{m} / \mathrm{sec})$

$\checkmark$ Gas velocity $(\mathrm{m} / \mathrm{sec})$

$v \quad$ Plasilla volume $\left(\mathrm{m}^{-3}\right)$

$X \quad$ Function

Greek Symbols

$\alpha \quad$ Total electron energy loss cross section $\left(\mathrm{m}^{2}\right)$

$\gamma \quad$ Ideal-gas specific heat ratio

$\xi \quad$ Heating parameter

$\lambda \quad$ Latent heat of vaporization $(\mathrm{eV} / \mathrm{Kg})$

$\rho \quad$ Mass density $\left(\mathrm{Kg} / \mathrm{m}^{3}\right)$

$\tau$. Pellet lifetime (sec)

\section{Subscripts}

- Pertaining to values at pellet surface

s Solid

- Piasma external to shielding gas cloud

\section{Superscripts}

$1 \quad$ Normalized to pellet surface values 


\section{REFERENCES}

1. P. B. Parks, R. J. Turnbul1, and C. A. Foster, "A Model for the Ablation Rate of a Solid Hydrogen Pellet in a Plasma," to be published in Nuclear Fusion.

2. W. T. Miles, R. Thompson, and A. E. S. Green, J. Appl. Phys. $\underline{43}(2), 678$ (1972).

3. A. H. Shapiro, The Dynamics and Thermodynamics of Compressible Fluid Flow, Vol. 1, Ronald Press, New York, 1953.

4. C. A. Foster, R. J. Colchin, S. L. Milora, K. Kim, and R. J. Turnbull, "Spherical Solid Hydrogen Injection Experiments on ORMAK," to be published.

5. C. A. Foster, R. J. Turnbull, and C. D. Hendricks, "An Apparatus for Producing Uniform Solid Spheres of Hydrogen," to be published in Review of Scientific Instruments.

6. M. Murakami (ORNL), private communication, 1976. 
THIS PAGE

WAS INTENTIONALLY

LEFT BLANK 
APPENDIX A

THE EFFECT OF. ELASTIC SCATTERING OF ELECTRONS ON THE ABLATION RATE

An essential element of the neutral ablation model is the assumption that heat is carried from the plasma to the pellet surface by electrons that stream through the molecular cloud along paths confined to magnetic field lines. In this manner the problem is reduced to that of a molecular beam incident on a gaseous target. In addition to the degradation of electron energy by inelastic collisions, which is described by the loss function $L\left(E_{e}\right)$, particles can be removed from the beam by elastic scattering which constitutes an additional energy. loss. An estimate of the effect that this has on the ablation rate can be made by treating electron scattering and energy loss as combined rather than separate processes. In this only slightly different formulation, the power flux incident on the pellet surface is reduced below that of the external piasma by an attenuation factor I. Equation. (6) then becomes

$$
\frac{d r_{0}}{d t}=-\frac{n_{e_{\infty}}}{\rho_{s}{ }^{\lambda}} \sqrt{\frac{4 e E_{e^{\infty}}}{27 \pi m_{e}}} \cdot I E_{e_{\infty}}
$$

In the usual manner, the factor $I$ is related to an appropriate cross section $\alpha$ and the integrated column density (of molecular hydrogen) by an exponentiai relationship. In terms of the relationship introduced in Sect. 2.2 the expression for I becomes

$$
I \equiv e^{-\alpha \frac{\rho_{U}}{m} r_{0} \int_{1}^{\infty} \rho^{\prime} d r^{\prime}}=e^{-\alpha \frac{\rho_{U}}{m} r_{0} f(\xi)}
$$

It was demonstrated in Sect. 2.2 (and Fig. 5) that $f(\xi) \approx 0.81 \xi^{-1 / 3}$ for values of parameter $\xi$ varying between 10 and 1000 . Using this information and the defining relationship for $\xi$ in (A2), the following alternate expression for the ablation rate results

$$
\frac{\mathrm{d} r_{0}}{\mathrm{~d} \hat{t}}=-0.51 \frac{m}{\rho_{\mathrm{s}}}\left(\frac{\mathrm{e}}{m_{\mathrm{e}}}\right)^{1 / 6}\left(\frac{\mathrm{e}}{m}\right)^{1 / 3} L\left(E_{\mathrm{e}^{\infty}} / 2\right)^{1 / 3} r_{0}^{-2 / 3} n_{\mathrm{e}^{\infty}}^{1 / 3} E_{\mathrm{e}_{\infty}}^{1 / 6} \frac{\ln \left(I^{-1}\right)}{\alpha}
$$


Equations (A1) and (A2) are the counterparts to Eqs. (6) and (21), respectively. The analogy can be carried even further if a correspondence is made between the product $I E_{e^{\infty}}$ and $E_{e_{0}}$. Equation ( $A 1$ ) then becomes identical to Eq. (6) and Eq. (A3) reduces to

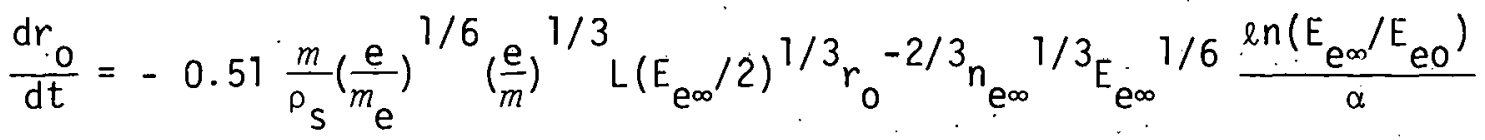

The form of Eq. (A4) is qualitatively very similar to Eq. '(21), the only difference being the factor $\alpha^{-1} \ln \left(E_{e^{\infty}} / E_{e o}\right)$ of the former replacing the integral relationship of the latter. For a given plasma energy and its associated value of $\alpha$, a comparison of these two terms alone determines the differences in the two formulations. In Fig. Al these two terms are plotted as a tunction of the surface energy $E_{e o}$ for $E_{e^{\infty}}=1$ kév and $\alpha=1.35 \times 10^{-21} \mathrm{~m}^{2}$. The latter was taken from the work of Heaps and Green ${ }^{1}$ who have calculated appropriate cross sections for given initial beam energies. As expected, the function which includes scattering is always smaller, but for surface energies below about $10 \mathrm{eV}$ the difference is not large. Since the presence of the shield ensures that surface energies will be below $10 \mathrm{eV}$, it is concluded that elastic scattering will not be dominant although it could reduce ablation rates by the order of $20-30 \%$ :

\section{REFERENCES}

1. M. G. Heaps and A. E. S. Green, J. App 1. Phys. 46 (11), 4718 (1975). 


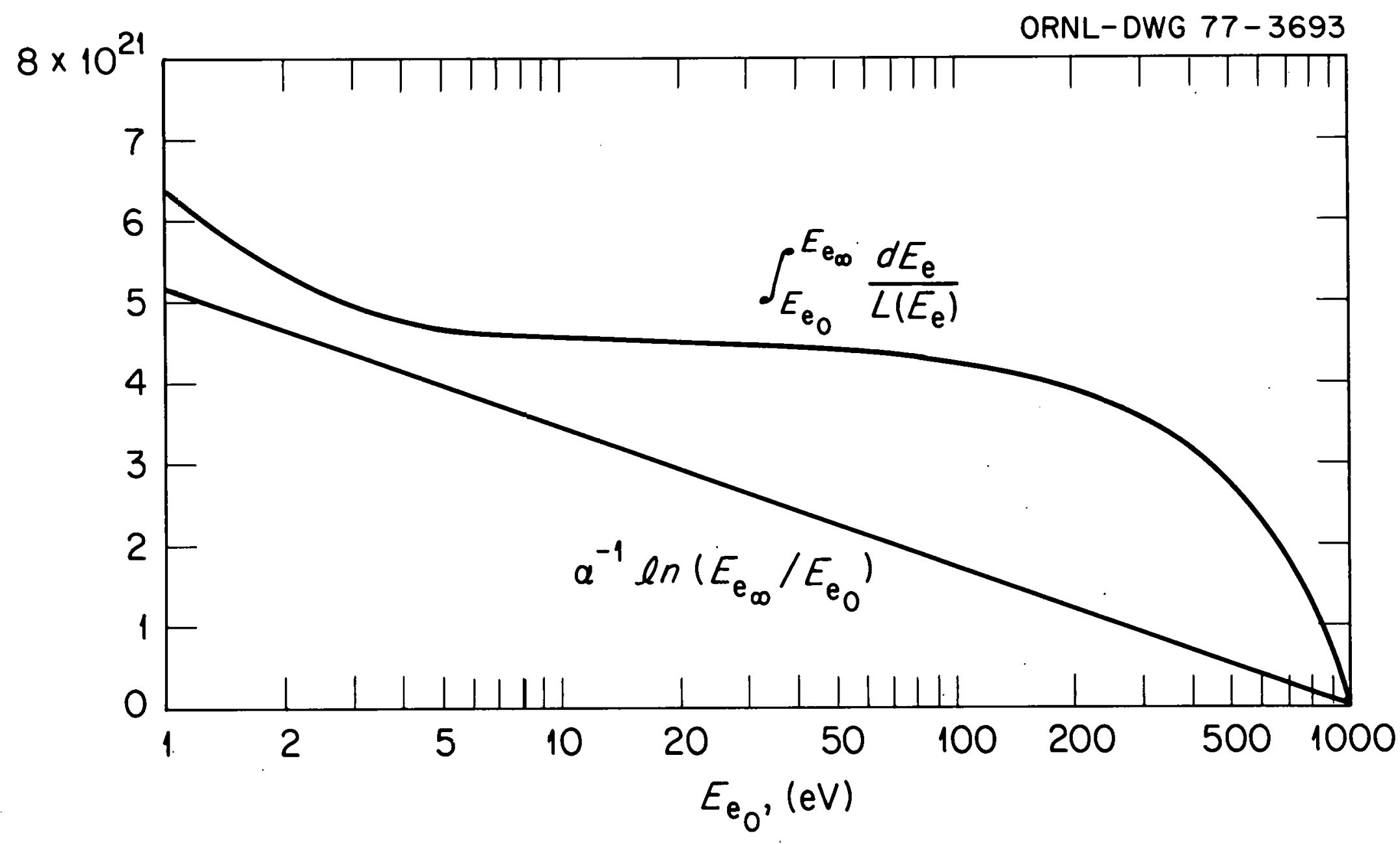

Fig. Al. Comparison of dissimilar terms of Eqs. (A4) and (21). 
THIS PAGE WAS INTENTIONALLY LEFT BLANK 
ORNL:/TM-5776

INTERNAL DISTRIBUTION

1. L. A. Berry

2. J. D. Callen

3. J. F. Clarke

4. R. J. Colchin

5. W. K. Dagenhart

6. R. A. Dandl

7-17. C. A. Foster

18. P. N. Haubenreich

19. T. C. Jernigan

20. G. G. Kelley

21. M. Lube11

22. J. F. Lyon

23. F. B. Marcus

24. A. T. Mense.

25-45. S. L. Milorà
46. 0. B. Morgan

47. M. Roberts

48. J. A. Rome

49. M. W. Rosenthal

50. G. Schilling

51. T. E. Shannon

52. D. Steiner

53. W. L. Stirling

54-55. Central Research Library

56. ORNL Document Reference Section

57-58. Laboratory Records Department

59. Laboratory Records, ORNL-RC

60. ORNL Patent Office

61-62. Fusion Energy Division Library

63. Fusion Energy Division Reports Office

\section{EXTERNAL DISTRIBUTION}

64. J. W. Bea 1, Development and Technology, Division of Magnetic Fusion Energy, Energy Research and Development Administration, Washington, DC. 20545

65. C. T. Chang, Physics Department, Research Establishment Ris $\varnothing-$ Danish AEC, Raskilide, Denmark, DF

66. H. S. Cullingford, Development and Technology, Division of Magnetic Fusion Energy, Energy Research and Development Adiiitiristration, Washington, DC 20545

67. S. 0. Dean, Assistant Director, Office of Confinement Systems, Division of Magnetic Fusion Energy, Energy Research and Development Administration, Washington, DC 20545

68. Harold K. Forsen, Exxon Nuclear Co., Inc., 777106 th Ave., NE, Bellevue, WA 98004

69. T. K. Fowler, University of California, Lawrence Livermore Laboratory, P.0. Box 808, Livermore, CA 94551

70. H. P. Furth, Plasma Physics Laboratory, Princeton University, P.0. Box 451, Princeton, NJ. 08540

71. S. Gralnick, Plasma Physics Laboratory, Princeton University, P.O. Box 451, Princeton, NJ 08540 
72. Dr. Otto Hagena, Kernforschungszentrum Karlsruhe, Post Fach 3640 , Federal Republic of Germany

73. T. Hsu, Development and Technology, Division of Magnetic Fusion Energy, Energy Research and Development Administration, Washington, DC 20545

74. V. 0. Jensen, Physics Department, Research Establishment Ris $\phi-$ Danish AEC, Raskilide, Denmark, DF

75. Dr. J. Junker, . Max Planck Institut für Plasmaphysik, Abteilung E2, 8046 Garching bei Munchen, Federa 1 Repub1ic of Germany

76. G. D. Kerbel, University of California, Lawrence Livermore Laboratory. P.ก. Rnx 808 , Livermorc, CA 04551

77. K. K. Kim, Department of Electrical Engineering, University of Illinois, Urbana, IL 61801

78. E. E. Kintner, Director, Division of Magnetic Fusion Energy, Energy Research and Development Administration, Washington, DC 20545

79. L. L. Lengyel, Max Planck Institut für Plasmaphysik, Abteilung E2, 8046 Garching bei Munchen, Federal Republic of Germany

80. Librarian, Culham Laboratory, UKAEA, Abingdon, Oxfordshire, $0 \times 1430 B$ England

81. Librarian, Institute for Plasma Physics, 8046 Garching bei Munchen, Ferderal Republic of Germany

82. C. E. Max, University of California, Lawrence Livermore Laboratnry, P.0. Bux 808, Liveermore LA 94551

83. D. G. McAlees, Exxon Nuclear Co., Inc., Research and Technology Center, 2955 George Washington Way, Richland, WA 99352

84. Dale Meade, Plasma Physics Laboratory, Princeton University, P.0. Box 451, Princeton, NJ 08540

85. Mike Murphy, Development and Technology, Division of Magnetic Fusion Energy, Energy Research and Development Administration, Washington, DC 20545

86. T. Ohkawa, General Atomic Company, Inc., P.0. Box 608, San Diego, CA 92112

87. P. B. Parks, General Atomic Company, Inc., P.0. Box 608, San Diego, CA 92112 
88. Plasma Physics Library, Plasma Physics Laboratory, Princeton University, P.0. Box 451, Princeton, NJ 08540

89. P. A. Politzer, Department of Nuclear Engineering, Massachusetts Institute of Technology, Cambridge, MA 02139

90. W. Riedmuller, Max Planck Institut für Plasmaphysik, Abteilung E2, 8046 Garching bei Munchen, Federal RepubTic of Germany

91. D. G. Rose, Department of Nuclear Engineering, Massachusetts Institute of Technology, Cambridge, MA 02139

92. M. Salvat, Max Planck Institut für Plasmaphysik, Abteilung E2, 8046 Garching bei Munchen, Federal Republic of Germany

93. Greg Schmidt, Plasma Physics Laboratory, Princeton University, P.0. Box 451, Princeton, NJ 08540

94. John Schmidt, Plasma Physics Laboratory, Princeton University, P.0. Box 451, Princeton, NJ 08540

95. F. R. Scott, Electric Power Research Institute, 3412 Hillview Ave., P.0. Box 10412, Palo Alto, CA 94303

96. T. Sekiguchi, University of Tokyo and IPP Nagoya, Tokyo, Japan

97. L. D. Stewart, Plasma Physics Laboratory, Princeton University, P.0. Box 451, Princeton, NJ 08540

98. C. E. Thomas, Department of Nuclear Engineering, Massachusetts Institute of Technology, Cambridge, MA 02139

99. R. J. Turnbul1, Department of Electrical Engineering, University of Illinois, Urbana, IL 61801

100. J. M. Williams, Assistant Director, Development and Technology, Division of Magnetic Fusion Energy, Energy Research and Development Administration, Washington, DC 20545

101. J. T. Woo, Massachusetts Institute of Technology, Rm. 38-176, Cambridge, MA 02139

102. Dr. H. H. Woodson, Chairman, Department of Electrical Engineering, the University of Texas at Austin, Austin, TX 78712

103. Director, Research and Technical Support Division, ERDA-ORO, P.0. Box E, Oak Ridge, TN 37830

104-130. Technical Information Center, Energy Research and Development Administration, P.0. Box 62, Oak Ridge, TN 37830 